NBER WORKING PAPER SERIES

THE INCIDENCE OF POLLUTION CONTROL POLICIES

\author{
Ian W.H. Parry \\ Hilary Sigman \\ Margaret Walls \\ Roberton C. Williams III \\ Working Paper 11438 \\ http://www.nber.org/papers/w11438 \\ NATIONAL BUREAU OF ECONOMIC RESEARCH \\ 1050 Massachusetts Avenue \\ Cambridge, MA 02138 \\ June 2005
}

We are grateful to Spencer Banzhaf, Henk Folmer, Adam Rose, Tom Tietenberg, and two reviewers for excellent comments and suggestions. This paper was prepared for the International Yearbook of Environmental and Resource Economics. The views expressed herein are those of the author(s) and do not necessarily reflect the views of the National Bureau of Economic Research.

(C2005 by Ian W.H. Parry, Hilary Sigman, Margaret Walls, and Roberton C. Williams III. All rights reserved. Short sections of text, not to exceed two paragraphs, may be quoted without explicit permission provided that full credit, including $\odot$ notice, is given to the source. 
The Incidence of Pollution Control Policies

Ian W.H. Parry, Hilary Sigman, Margaret Walls, and Roberton C. Williams III

NBER Working Paper No. 11438

June 2005

JEL No. Q52, H23, H22

\section{ABSTRACT}

This paper reviews theoretical and empirical literature on the household distribution of the costs and benefits of pollution control policies, and ways of integrating distributional issues into environmental cost/benefit analysis. Most studies find that policy costs fall disproportionately on poorer groups, though this is less pronounced when lifetime income is used, and policies affect prices of inputs used pervasively across the economy. The policy instrument itself is also critical; freely allocated emission permits may hurt the poor the most, as they transfer income to shareholders via scarcity rents created by higher prices, while emissions taxes offer opportunities for progressive revenue recycling. And although low-income households appear to bear a disproportionate share of environmental risks, policies that reduce risks are not always progressive, for example, they may alter property values in ways that benefit the wealthy. The review concludes by noting a number of areas where future research is badly needed.

Ian W.H. Parry

Resources for the Future

1616 P Street

Washington, DC 20036

parry@rff.org

Hilary Sigman

Department of Economics

Rutgers University

75 Hamilton Street

New Brunswick, NJ 08901-1248

and NBER

sigman@econ.rutgers.edu
Margaret Walls

Resources for the Future

1616 P Street

Washington, DC 20036

walls@rff.org

Roberton C. Williams III

Department of Economics

University of Texas

1 University Station \#C3100

Austin, TX 78712

and NBER

rwilliam@eco.texas.edu 


\title{
The Incidence of Pollution Control Policies
}

\begin{abstract}
This paper reviews theoretical and empirical literature on the household distribution of the costs and benefits of pollution control policies, and ways of integrating distributional issues into environmental cost/benefit analysis. Most studies find that policy costs fall disproportionately on poorer groups, though this is less pronounced when lifetime income is used, and policies affect prices of inputs used pervasively across the economy. The policy instrument itself is also critical; freely allocated emission permits may hurt the poor the most, as they transfer income to shareholders via scarcity rents created by higher prices, while emissions taxes offer opportunities for progressive revenue recycling. And although low-income households appear to bear a disproportionate share of environmental risks, policies that reduce risks are not always progressive, for example, they may alter property values in ways that benefit the wealthy. The review concludes by noting a number of areas where future research is badly needed.
\end{abstract}

\section{INTRODUCTION}

Economic evaluations of pollution control policies have traditionally focused on pure efficiency effects - either a comparison of their economic costs and environmental benefits, or a comparison of their costs relative to those of alternative control policies (e.g., Cropper and Oates 1992, Morgenstern 1997, Hahn 2005). However, the distribution of policy costs and benefits across households and firms is receiving increasing attention among researchers and policymakers. ${ }^{1}$ One reason is concern about whether a policy is "fair" or not. Another is political feasibility — a policy justifiable on efficiency grounds may be impractical if it imposes a disproportionate burden on a politically influential group. Often the two are critically related; for example, political opposition to higher fuel taxes, carbon taxes, or other emissions taxes in the United States is frequently based on the claim that such taxes fall most heavily on low-income groups. The purpose of this paper is to summarize what is actually known, and not known, about the incidence of benefits and costs from pollution taxes, and alternative emissions control measures, across household income groups.

Distributional issues have many diverse dimensions and we omit a number of topics, some of which have been comprehensively reviewed elsewhere. We do not discuss racial incidence. Evidence on this is discussed in Hamilton (2005); the main finding is that, in addition to income, other factors such as lack of participation in local decision-making, explain the disproportionate burden of environmental risks borne by minorities. We only briefly touch on incidence across consumers versus producers and across

\footnotetext{
${ }^{1}$ For example, in 1994 the Clinton Administration directed the EPA to study the pattern of environmental hazards across different income and racial groups and to explore options for reducing disparities.
} 
capital versus labor; Fullerton and Metcalf (2002) have recently reviewed the extensive public finance literature on such issues. And we do not discuss regional incidence within a country, nor intergenerational and inter-country incidence. ${ }^{2}$ Finally, most of our discussion applies to local and global air pollution policies in the United States and Europe, as that is where the bulk of empirical efforts have been focused. ${ }^{3}$

The paper is organized as follows. Section 2 provides a conceptual framework for understanding and measuring the burden on different income groups from the costs of alternative emissions control instruments. Section 3 summarizes various empirical studies on how the costs of emissions taxes, emissions permits, and command and control policies are distributed across households. Section 4 discusses the distributional pattern of benefits from emissions control policies. Section 5 briefly discusses three ways in which distributional considerations might be integrated into traditional cost/benefit analyses of environmental policies. Section 6 summarizes the main findings from the review and lists important topics for future research.

\section{CONCEPTUAL ISSUES}

This section provides a highly simplified theoretical framework to help interpret results from more sophisticated empirical models discussed in Section 3. Our main focus is on pollution taxes in a competitive, partial equilibrium setting; we also touch on measurement issues, other forms of regulation, and complications due to non-competitive pricing and general equilibrium effects.

\subsection{Pollution Taxes}

2.1.1. Product Taxes. To start with, consider the taxation of a single polluting commodity $X$ (e.g., gasoline, electricity) which is produced by competitive firms under constant returns and consumed by all $i$ $=1 \ldots N$ individuals in the economy. Individuals differ according to income level $I_{i}$. Prior to the introduction of the tax, the product price $p_{X}=p_{X}^{0}$, where $p_{X}^{0}$ is the producer price, consumption for household $i$ is $X_{i}^{0}$, and consumer surplus is triangle $a b c$ in Figure 1. With a specific tax $t_{X}$ the consumer price is $p_{X}^{1}=p_{X}^{0}+t_{X}$; the burden of the tax for household $i$, prior to recycling of revenues, is the

\footnotetext{
${ }^{2}$ The latter two issues are particularly contentious in climate policy. Estimated future damages from atmospheric accumulation of greenhouse gases are highly sensitive to assumptions about long range discount rates, and whether different weights are attached to the welfare of poor nations that are most vulnerable to climate change (see e.g., Portney and Weyant 1999, Azar and Sterner 1996, Carraro 2000, Stevens and Rose 2002).

${ }^{3}$ We do not cover incidence of solid waste policies and noise pollution; for some discussion of these issues see Kinnaman and Fullerton (2000), Feitelson et al. (1996), and Ashenmiller (2004).
} 
consumer surplus loss, trapezoid decb in Figure 1. This consists of the first order tax payment rectangle degb equal to $t_{X} X_{i}^{1}$, and a second order loss from the reduction in consumption, triangle ecg equal to $-\left(\partial X_{i} / \partial p_{X}\right)\left(t_{X}\right)^{2} / 2$ (assuming linear demand over the relevant range). Alternatively, the burden is the tax payment with no change in consumption rectangle $d f c b$ equal to $t_{X} X_{i}^{0}$, less triangle efc equal to $-\left(\partial X_{i} / \partial p_{X}\right)\left(t_{X}\right)^{2} / 2$, the saving in spending, net of forgone consumption benefits, from the reduction in consumption.

We define the (initial) own-price elasticity of demand for household $i$ by $\eta_{X i}=\left(\partial X_{i} / \partial p_{X}\right) p_{X}^{0} / X_{i}^{0}<0$. Using this and the above expressions, the burden to household $i\left(B_{i}\right)$ can be written:

$$
B_{i}=t_{X} X_{i}^{1}-\left(t_{X} / p_{X}^{0}\right)^{2} p_{X}^{0} X_{i}^{0} \eta_{X i} / 2=t_{X} X_{i}^{0}+\left(t_{X} / p_{X}^{0}\right)^{2} p_{X}^{0} X_{i}^{0} \eta_{X i} / 2
$$

For small tax changes the second order effect from the behavioral response to the tax is small relative to the first order effect of the price increase (ecg is small relative to degb, or efc is small relative to $d f c b$, in Figure 1); thus it is reasonable to ignore the second order effect. In this case the burden, expressed relative to income, is approximately given by:

$$
B_{i} / I_{i} \approx\left(t_{X} / p_{X}^{0}\right) s_{X i}^{0}
$$

where $s_{X i}^{0}=p_{X}^{0} X_{i}^{0} / I_{i}$ is the (initial) budget share. In this case, whether policy costs are progressive/proportional/regressive (i.e. whether the burden relative to income rises, is constant or falls with income) depends on whether the budget share is lower/the same/greater for low-income households than for high-income households.

2.1.2. Emissions taxes. Efficient environmental taxes are levied on emissions, rather than a consumption good, and thus ultimately may affect final product prices across a range of industries. Suppose a tax of $t_{E}$ is levied on pollution emissions and that emissions are released during the production of $j=1 \ldots M$ consumption goods. Firms producing good $j$ will reduce emissions per unit of output until the incremental abatement cost (e.g., from end-of-pipe treatment or from substituting cleaner inputs in production) equals the emissions tax. In Figure 2, the tax-induced abatement is therefore $e_{j}^{0}-e_{j}$, where $e_{j}$ denotes emissions per unit of output. Assuming firm costs are fully passed forward to consumers (see below), the price of good $j$ is:

$$
p_{j}^{1}=t_{E} e_{j}+c_{j}\left(e_{j}^{0}-e_{j}\right)+p_{j}^{0}
$$


where $t_{E} e_{j}$ is the emissions tax payment per unit of output, rectangle $a c d b$ in Figure $2, c_{j}($.$) is the$ resource cost from abatement per unit of output, area $0 a b$, and $p_{j}^{0}$ is the initial producer price.

Using analogous expressions to (2.1) for the burden of price increases, aggregating over all goods and dividing by income, the burden of the emissions tax can be expressed:

$$
\begin{aligned}
& B_{i} / I_{i}=\sum_{j=1}^{M} \hat{p}_{j} s_{j i}^{0}+\frac{1}{2} \sum_{j=1}^{M} \hat{p}_{j}^{2} \eta_{i j}^{0} s_{j i}^{0} \\
& \hat{p}_{j}=\left(p_{j}^{1}-p_{j}^{0}\right) / p_{j}^{0}=\left(t_{E} e_{j}+c_{j}(.)\right) / p_{j}^{0}, \quad s_{j i}^{0}=p_{j}^{0} X_{j i}^{0} / I_{i}
\end{aligned}
$$

where $\hat{p}_{j}$ is the proportionate increase in price of product $j$ and $s_{j i}^{0}$ is household $i$ 's (initial) budget share for good $j$. As before, the burden amounts to first order surplus losses from the increase in prices at initial consumption, less second order gains from the reduction in consumption. And ignoring the second order terms is reasonable when the proportionate change in product prices is small ( $\hat{p}_{j}^{2}$ is small relative to $\hat{p}_{j}$ ).

2.1.3. Revenue Recycling. Many empirical studies do not consider recycling of environmental tax revenues in other tax reductions, even though overall incidence impacts are very sensitive to the form of recycling. Consider, for example, the case of one polluting good. With $\Delta \hat{p}$ small, the burden with revenue recycling for household $i$ would be

$$
B_{i} / I_{i} \approx \hat{p} s_{i}^{0}-\alpha_{i}
$$

where $\alpha_{i}$ is the rebate from revenue recycling as a proportion of household i's income. Clearly, the regressivity of the tax could be reduced if the rebate were larger as a fraction of income for low-income households than for high-income households (for example, if revenues financed an increase in income tax thresholds).

2.1.4. Indexing of Transfer Payments. Many transfer programs (e.g., social security) are indexed for price changes suggesting that low-income households may receive some compensation, even prior to recycling of revenues. This is a significant consideration, taken into account in some studies. However, not all lowincome households receive transfer payments; moreover, low-income families often have relatively high budget shares for energy and polluting goods, implying that they will be under-compensated from price indices that weight these goods according to budget shares of the average household.

\subsection{Measurement Issues}


We now comment briefly on the measurement of variables that enter into the net burden formula (2.4).

2.2.1. Household Expenditure on Final Products. This is available from household data sources, such as the Consumer Expenditure Survey (CES) in the United States.

2.2.2. Household Income. Measurement of household income is tricky. In principle lifetime income is a better measure of an individual's well being than current income. For example, Harvard MBA students may have low current income, but are not poor in a lifetime context given their high, expected future earnings. In addition, a reasonably well-off person may appear poor in a particular year due to transitory factors, such as temporary unemployment, illness, extended maternity leave, etc. Lifetime measures of income are designed to remove the confounding effects of similar people being at different stages of their lifecycle, and short-term variation in earnings; incidence estimates based on lifetime income tend to be significantly less regressive than those based on annual income.

However, lifetime income is far more difficult to measure than current income, as it requires tracking households over extremely long time periods. Earlier studies by Poterba (1989) of federal excise taxes and Metcalf (1994) of state and local sales taxes, proxied lifetime income by annual consumption, based on the Friedman/Modigliani permanent income and lifecycle models; with perfect lifecycle consumption smoothing, current consumption is proportional to lifetime income. However evidence suggests that the lifetime consumption trajectory is not flat but has an inverted-U shape, due in part to liquidity constraints (e.g., Bull et al. 1994, Zeldes 1989, Souleles 1999 and 2002), and that consumption is responsive to changes in the timing of income (Shapiro and Slemrod, 1994); these findings are inconsistent with the lifetime income hypothesis. Some more recent studies therefore use econometric methods relating income to education, age, and other demographic variables to construct more sophisticated measures of lifetime income. ${ }^{4}$ Even this approach is not entirely satisfactory, as it does not consider all potentially important factors determining income and it implicitly assumes that the status of a person observed at a single point in time stays the same forever; ${ }^{5}$ some authors even argue against using

\footnotetext{
${ }^{4}$ See for example Fullerton and Rogers (1993), Casperson and Metcalf (1994), Walls and Hansen (1999), Slesnick (1994), and the discussion in Metcalf (1999). An alternative approach is cohort analysis (e.g., Gale et al. 1996), which considers only households at similar stages of their life cycle; however this approach does not address the problem of annual income variation.

${ }^{5}$ For example, if we observe that a person has 14 years of education, we have know way of knowing whether they will go to college for two more years and earn a Bachelors degree or not.
} 
the lifetime income concept in policy analysis at all (Barthold, 1993). Given the controversy surrounding income measurement, studies often report results for a range of alternative income definitions.

2.2.2. Change in Product Prices. The tax component of changes in final goods prices can be obtained using input-output tables that trace all intermediate goods going into final goods production (e.g., from the Bureau of Economic Analysis), and data on emissions factors for polluting inputs (e.g., from EPA 1996). Direct estimates of the abatement cost component of price increases might be unavailable, and are often ignored, which is reasonable so long as the proportionate emissions reduction is modest. ${ }^{6}$

2.2.3. Demand Elasticities. Estimates of product demand elasticities for different household income groups have only recently begun to emerge from analyses of micro data (e.g., West 2004a). Previous empirical studies that included behavioral responses usually assumed proportionate demand changes were the same across all households.

One subtle issue is that the second-order component of the change in household welfare differs according to whether it is measured by consumer surplus, equivalent variation, or compensating variation; in the former case the welfare change is the relevant area under the uncompensated demand curve, while in the latter cases it is measured with respect to compensated demand curves. For individual product price increases there is usually very little difference between the three welfare measures, so long as the share of spending on this good is a small fraction of income; ${ }^{7}$ but this may not be the case when a wide range of product prices are simultaneously increased, and the relevant budget share is more substantial.

\subsection{Other Control Instruments}

For simplicity, in the discussion below we assume an emissions policy affects the price of just one commodity $X$.

2.3.1. Tradable Emissions Permits. Tradable permits have essentially the same distributional effects as an emissions tax that would induce the equivalent emissions reduction, if the permits are fully auctioned.

\footnotetext{
${ }^{6}$ If abatement costs are unknown they could be approximated by $t_{E}\left(e_{j}^{0}-e_{j}\right) / 2$, if it is reasonable to assume marginal costs are linear over the relevant range (this is easily seen from Figure 2). If not, abatement costs can be bounded by $\left\{0, t_{E}\left(e_{0}-e\right)\right\}$.

${ }^{7}$ See Willig (1976). From the Slutsky equation, the difference between the uncompensated and compensated ownprice demand elasticity equals the income elasticity times the budget share.
} 
That is, if the equilibrium permit price is $\tau$, then analogous expressions to equations (2.3) and (2.4) apply again, with $t_{E}$ replaced by $\tau^{8}$

Effects are quite different, however, if permits are given out for free (Dinan and Rogers 2002, Parry 2004). ${ }^{9}$ The reason is that, rather than going to the government, permit rents are reflected in higher firm equity values because firms receive an asset with market value for free. The permit cap acts rather like a binding production quota, or a cartel where members agree to limit their production; in all cases output is reduced below free market levels and product prices and firm profits are increased. Ultimately permit rents accrue to households in the form of dividends or capital gains; in terms of equation (2.4a), there is now an income term, $\pi_{i} / I_{i}$, subtracted from the right-hand side, where $\pi_{i}$ is profit income for household $i$ arising from permit rents. To the extent that wealthy households receive a greater share of their income from capital than poor households, that is $\pi_{i} / I_{i}$ increases with $I_{i}$, the creation of scarcity rents is regressive.

In fact, it is possible that high-income households are actually made better off under grandfathered permits (excluding environmental benefits), while low-income households are substantially worse off! To see this suppose, for simplicity, that half the population has high income $(H)$, the other half has low income $(L)$, and high-income households own all the capital. Suppose also that we can ignore second order effects. Then burden for high- and low-income households is given by:

$$
B_{H} \approx\left(p_{X}^{1}-p_{X}^{0}\right) X_{H}^{0}-\pi_{H}, \quad B_{L} \approx\left(p_{X}^{1}-p_{X}^{0}\right) X_{L}^{0}
$$

where $p_{X}^{1}-p_{X}^{0}=\tau e+c\left(e_{X}^{0}-e_{X}\right)$ is the product price increase and $\pi_{H}$ is capital or profit income per high-income household. The latter equals the permit rents $\tau e\left(X_{L}^{0}+X_{H}^{0}\right)$, equal to the permit price $\tau$ times emissions $e\left(X_{L}^{0}+X_{H}^{0}\right)$. Low-income households receive no compensation and are unambiguously worse off $\left(B_{L}>0\right)$. However high-income households could be better off overall $\left(B_{H}<0\right)$; in our highly simplified example, this occurs when permit rents are large enough relative to abatement costs so that $\left.\tau e\left(X_{H}^{0}+X_{L}^{0}\right)>(\tau e+c) X_{H}^{0}\right)$ or $\tau e / c>X_{H}^{0} / X_{L}^{0}$.

Several subtle considerations weaken, though not necessarily overturn, the prospects for this perverse equity effect. First, the share of permit rents, vis-à-vis the share of abatement costs, in the

\footnotetext{
${ }^{8}$ For each unit of emissions firms must either buy a permit from other firms, or forgo selling one of their permits; either way the cost to the firm is $\tau$, and firms will abatement until the incremental cost equals $\tau$. This leaves aside some complications, such as transactions costs to permit trading and uncertainty over control costs.

${ }^{9}$ Nearly all permits have been given out for free in existing programs, including those to reduce the lead content of gasoline, ozone-depleting chemicals, and utility emissions of $\mathrm{SO}_{2}$ in the United States, and the $\mathrm{CO}_{2}$ trading program introduced in the European Union in January 2005.
} 
product price increase typically diminishes at higher levels of abatement, at least with linear (though perhaps not convex) marginal abatement costs, that is, $\tau e$ (rectangle $a c d b$ in Figure 2) decreases in size relative to $c$ (.) (triangle $0 a b$ ). Thus, the prospects for rent income to overcompensate high-income households for the price increase diminishes with the level of abatement. Second, a significant portion of the permit rents (around 35\% in the United States) will still go, albeit indirectly, to the government rather than owners of capital, via corporate taxes paid on additional profits, and personal income and capital gains taxes on additional household income. Third, capital income is not exclusively earned by highincome households; even low-income households may have some capital income in the form of retirement accounts. ${ }^{10}$ Fourth, as discussed below, the price effects of tradable permits, and hence the rent transfer from consumers to shareholders, is sensitive to assumptions about returns to scale, market structure, and possible differences between marginal and non-marginal production technologies.

2.3.2. Command and Control Regulation. Suppose firms must satisfy a performance standard that imposes a limitation of $\bar{e}$ on emissions per unit of output. With homogeneous firms each firm's abatement cost per unit is $c\left(e^{0}-\bar{e}\right)$ and the product price is $p_{X}^{1}=c\left(e^{0}-\bar{e}\right)+p_{X}^{0}$. That is, there is no tax revenue/permit rent component to the price increase. ${ }^{11}$ Thus, the policy avoids the adverse distributional consequence of freely allocated permits that arises from the transfer of rent income to highincome households; whether the policy is progressive or regressive essentially depends on budget shares across income groups.

In fact, for a given emissions reduction, low-income households could be worse off under grandfathered permits than under the performance standard; although the pure abatement costs are lower under permits, the difference could be more than offset by the price effect of permit rents (Goulder et al. 1999). The same qualitative result could still apply, though is less likely, if firms are heterogeneous (and abatement costs are not minimized across firms), or under an end-of-pipe technology mandate (where

\footnotetext{
${ }^{10}$ For the United States, total stock and bond ownership across households can be measured from the CES; Dinan and Rogers (2002) and Parry (2004) compute that the top income quintile owns $86 \%$ and 53\% of total stocks, respectively. The difference is that Parry includes retirement capital, which is more evenly dispersed among income groups than non-retirement financial capital, while Dinan and Rogers exclude it.

Ideally information should be used on stock ownership in polluting firms, rather than total stock ownership across all firms, but the former is particularly difficult to obtain, given households own most of their stocks indirectly through large institutional investors.

${ }^{11}$ This is because there is no binding quota imposed on economy-wide emissions; new firms are free to enter the market without having to buy emissions permits from incumbent firms. Similarly, no rents would be created if the government took an existing command and control system and allowed firms to trade credits, unless the government also imposed a cap on economy wide emissions below the initial level.
} 
firms cannot exploit the least-cost combination of measures to reduce emissions per unit of output, including substitution of clean for dirty inputs).

\subsection{Complicating Factors}

So far we have assumed that all policy costs are fully passed forward to consumers, the standard approach taken in input-output analyses discussed below. However there are various complications that may affect the impact of environmental policies on product prices, and policies may also affect prices in (economy-wide) factor markets.

2.4.1. Upward Sloping Supply Curves. Even in the long run supply curves may still be upward sloping (rather than perfectly elastic as assumed above), due to rising marginal costs of using an input, such as a scarce natural resource, or industry-specific capital. In this case part of the burden of an emissions tax or other regulation will come at the expense of reducing producer prices and producer surplus, or pure firm profits, rather than higher product prices. This ultimately passes some of the burden back to shareholders in the form of lower equity values or dividend payouts. The effect is progressive since wealthier households earn a larger share of their income from capital.

2.4.2. Non-Competitive Pricing. The assumption of competitive pricing may be unrealistic; this is particularly the case for electricity generation, which is a major contributor to global and local air pollution. Currently, well over half of generated electricity in the United States is subject to regulated prices, though this fraction will diminish in future with continued restructuring (Brennan et al. 2002). In states where generation prices are regulated, the opportunity cost of using grandfathered permits to cover emissions is not passed on in higher prices (Burtraw et al. 2001, pp. 7). But even in deregulated markets, abatement costs may in part come at the expense of profits (and ultimately shareholders) rather than being fully passed forward, if firms have market power (e.g., Borenstein et al. 2002). Dominant firms may exercise market power in regional electricity markets when fringe competitors become capacity constrained at peak period, and congestion on the grid prevents the import of power from other regions.

2.4.3. Multiple Production Technologies. In electricity generation different technologies are often used to supply baseload and peak demand. At peak period infra-marginal production is often from coal plants, which have a high emissions intensity, while marginal production is often from natural gas plants, which have lower emissions intensity (in the case of carbon and $\mathrm{NO}_{\mathrm{x}}$ ) or zero emissions (in the case of SO2). Consequently, abatement costs for coal plants at peak period will not be fully passed on in higher prices; they will, at least in part, come at the expense of rents earned on infra-marginal production (in Parry's 
2005 analysis of the $\mathrm{SO}_{2}$ trading program this dampens the effect on product prices by about 45\%). Again, some of the burden is passed back to owners of capital.

2.4.4. Changes in Economy-wide Factor Prices. A recent general equilibrium analysis by Fullerton and Heutel (2004) explores the extent to which pollution taxes affect the economy-wide rate of return from capital relative to that from labor. They study a closed economy with labor and capital in fixed aggregate supply but mobile across industries, and two competitive, constant returns industries producing a clean good and a dirty good. They show that if the elasticity of substitution between polluting inputs and labor is the same as that for polluting inputs and capital, then a pollution tax will usually lower the relative return of the factor that is used more intensively in the dirty sector. Polluting industries tend to be relatively capital intensive (Antweiler et al. 2001, p. 879), implying that emissions taxes may enact a transfer from (wealthy) households with a relatively high capital income share to (poor) households with a relatively high labor income share. In this regard, most empirical studies of pollution control incidence may overstate policy regressivity, as they do not account for changes in economy-wide factor prices. ${ }^{12}$

\section{EMPIRICAL STUDIES}

This section begins by discussing the sizeable empirical literature on environmental taxes, and the much more limited one on emissions permits; for these policies the primary incidence effects are transparent, assuming tax payments or permit rents are fully passed on in higher prices. We then summarize older literature on command and control policies and overall federal environmental programs in the United States. Here, price effects must be inferred from estimates of abatement costs, which may be inaccurate since analysts and researchers often have imperfect information on firms’ costs.

Care is needed in comparing studies as they may measure incidence and household income differently, some studies account for behavioral responses to price rises induced by the policies while others do not, and some rely on a partial equilibrium framework while others take a general equilibrium approach.

\subsection{Environmental Taxes}

${ }^{12}$ However, results from general equilibrium incidence models are notoriously complex and ambiguous. For example, to the extent that the net return on capital is determined on world capital markets, this will cushion the potential fall in the relative return to capital. On the other hand, allowing for imperfect mobility of capital across industries may increase the burden that can be borne by capital. And more generally results also depend on the relative substitutability of labor and capital for polluting inputs, about which very little is known. Theoretical results on the general equilibrium incidence of pollution mandates have similar ambiguities (Fullerton and Heutel 2005). 
A substantial literature exists on a variety of energy taxes, including, gasoline and carbon taxes, and this forms the bulk of the work reviewed here. A general finding is that, prior to revenue recycling and on the basis of annual income, most environmental taxes look regressive because lower income households tend to spend a disproportionately larger fraction of their income on energy, which is a necessity good. Using lifetime income, taking account of increases in prices of other goods for which energy is an input, and recycling revenues can mitigate this regressivity, at least in part. Our review captures some of the most important published work in the area but is not meant to be exhaustive; rather, we provide a flavor for the literature, and note consensus on results if and where it exists.

\subsubsection{Gasoline Taxes}

A gasoline tax is, for the most part, a final product tax and thus has effects as we described in section 2.1.1 above. Poterba's (1989) study of gasoline taxes (and other federal excise taxes) was among the first to emphasize the quantitative significance of different measures of income for the degree of regressivity (see also Poterba 1991). He used CES data and computed the budget share on gasoline for each household. He found that the budget share of the bottom income quintile was 5.3 times that for the top income quintile when annual income is used, but 1.5 times that for the top income quintile when lifetime income, as proxied by annual consumption expenditure, is used.

Using data from the CES, West and Williams (2004) examine the incidence of an increase in the (federal and state) gasoline tax from its current level of about $\$ 0.40$ per gallon to $\$ 1$ per gallon, again with consumption as a proxy for lifetime income. Unlike Poterba, they account for behavioral responses in their incidence calculations, by econometrically estimating gasoline demand elasticities by income quintile. They find that the gasoline tax is generally regressive prior to revenue recycling. Regressivity is reduced if revenues are returned through an equal percentage reduction in the marginal tax rate on labor income for each income group. This occurs because labor income is a greater fraction of total income for low-income households than for high-income households. The regressivity of the gasoline tax increase is eliminated altogether if revenues are returned in equal lump-sum transfers for all households; in fact, in this scenario, the bottom two quintiles are actually better off overall. The authors also find that ignoring demand responses (i.e. computing rectangle $d f c b$ rather than trapezoid decb in Figure 1), or assuming the same gasoline demand elasticity across different income groups, makes the tax increase appear more regressive; this is because lower income groups have more elastic demands for gasoline, implying a disproportionate reduction in their burden from demand responses. Finally, they find little discrepancy in incidence effects between welfare measures based on consumer surplus and equivalent variation.

Although revenues from a future fuel tax increase might finance other tax cuts, revenues from the current fuel tax are earmarked for highways. Interestingly, Wiese et al. (1995), using a computational 
general equilibrium model, find that existing gasoline taxes are actually progressive, as highway spending bids up the demand for manual labor and relative wages of the bottom income quartile. Progressivity declines if some of the tax receipts are instead diverted to the general government and deficit reduction.

Bento et al. (2005) use the 2001 National Highway Transportation Survey (NHTS), a large US household survey dataset, to estimate a random coefficients model of vehicle choice and miles traveled, and combine that with a model of vehicle scrappage as well as a model of Bertrand competition (across manufacturers) in the new car market. They simulate a 10, 30, and 50 cent per gallon increase in the gasoline tax under scenarios when revenues are rebated to households in proportion to their gasoline tax payments and in proportion to income. The authors find that with tax-based recycling, the impact of the tax across income groups is close to proportional. With income-based recycling, on the other hand, lowincome households pay more as a percentage of income than high-income households. ${ }^{13}$

\subsubsection{Other Energy Taxes and Carbon Taxes}

The studies just discussed assume that gasoline is a final good, directly consumed by households; this is reasonable, because household consumption accounts for the bulk of gasoline use. However, it is not reasonable for many other goods that might be taxed on environmental grounds. For example, direct household consumption accounts for only about two-fifths of electricity sales; the remainder is split about equally between industrial and commercial users, and is effectively an intermediate good in the production of consumer products. In this case it is potentially important to account for increases in prices of other final goods that are indirectly affected by the tax.

In their study of taxes on electricity, coal, natural gas, gasoline and other refined petroleum products, Casler and Rafiqui (1993) compute price effects on 89 final goods consumed by households, using input-output tables. They assume that taxes are fully passed forward to consumers, and that firm's input-output ratios and household product demands are fixed. Price calculations are combined with CES data on the 89 commodities by income quintile, and income is measured on an annual basis. They find that the greater the share of output from the taxed good that is an intermediate, as opposed to final good, the less regressive the tax. Overall, the tax burden to income ratio for the lowest quintile is only modestly larger than that for the top quintile across the various taxes.

Bull et al. (1994) use the same data sources and a similar approach to analyze a tax based on energy content, i.e., a Btu tax, and a tax based on carbon content. However, they consider a broader range of household income measures than Casler and Rafiqui, including annual income, annual consumption,

\footnotetext{
${ }^{13}$ Although Bento et al. allow for scrappage and changes in vehicle holdings, their simulations only consider impacts in the first year after the policy and not longer run impacts. Future work by the authors will conduct a more long-run analysis.
} 
and lifetime income. ${ }^{14}$ Like Casler and Rafiqui, they find that on the basis of annual income the direct components of Btu and carbon taxes look quite regressive, while the indirect components are less regressive. On the basis of lifetime income, the direct component remains regressive but the indirect component becomes mildly progressive; overall, the taxes look much less regressive on a lifetime income basis than on an annual income basis.

In a third study employing similar data and methods, Metcalf (1999) analyzes a revenue-neutral package of environmental taxes, including a carbon tax, an increase in motor fuel taxes, taxes on various stationary source emissions, and a virgin materials tax; revenues from this package amount to $10 \%$ of federal income tax revenue. Prices of energy goods-electricity, natural gas, fuel oil and gasoline —increase substantially under these measures (by 14 to 27\%), while prices of all other consumer goods increase by less than 5\%. Although the taxes disproportionately hit low-income groups, Metcalf shows that the overall package can be made distributionally neutral (under a range of different income measures) through careful targeting of income and payroll tax reductions.

Cornwell and Creedy (1997) use data from the1984 Australian Household Expenditure Survey to estimate parameters of a linear expenditure system for different income groups and then use these parameters to calculate compensating and equivalent variations resulting from a carbon tax. The authors assume that the carbon tax is fully passed forward to consumers and that the prices of goods increase in proportion to their carbon content. They find that the tax is regressive, on the basis of annual income: both compensating and equivalent variation as a fraction of income fall as income rises. They also show how a "minimum income guarantee" could be increased and offset the regressive effects of the tax.

Brännlund and Nördstrom (2004) use data from Sweden to analyze a carbon tax with revenues recycled in a reduction in the general value-added tax (VAT), or in a reduction in the VAT on public transport. ${ }^{15}$ The authors use the Swedish Household Expenditure Survey, combined with aggregate data from the National Accounts, to estimate the demand for nondurable goods. They obtain price elasticities that vary by income quintile then simulate the effects of the tax policies. They find that the tax is regressive under the first recycling scenario, but less regressive in the second. Larger differences show up regionally in the second scenario_ _ city dwellers benefit from the policy while rural households are hurt.

\footnotetext{
${ }^{14}$ The lifetime measure is obtained by calculating a "typical" consumption path for various subgroups defined by age and education, and constructing lifetime consumption for each individual in the sample by scaling their current consumption relative to the average for their age/education subgroup. A similar exercise is carried out to obtain measures of lifetime direct and indirect energy taxes paid; lifetime incidence is lifetime taxes paid as a percentage of lifetime consumption.

${ }^{15}$ For revenue neutrality in the second scenario, they end up with an ad valorem transport subsidy of $23 \%$.
} 
Unlike other studies that consider proposed carbon taxes, Wier et al. (2005) examine the existing $\mathrm{CO}_{2}$ tax in Denmark, based on actual taxes paid directly and indirectly by households. They use inputoutput tables from Denmark for the year 1996, assuming taxes are fully passed through to consumers in higher product prices, and a consumer expenditure survey of over 3,400 households. On the basis of annual income, Wier et al. find that (excluding use of revenues) the $\mathrm{CO}_{2}$ tax is regressive: households in the lowest income decile paid approximately $0.8 \%$ of their disposable income in taxes, while households in the highest decile paid less than $0.3 \%$. Again, the direct component of the tax accounts for most of the regressivity. Using total expenditures as a proxy for lifetime income, Wier et al. find that the regressivity is greatly reduced, though not entirely eliminated.

\subsubsection{Motor Vehicle Taxes}

Walls and Hanson (1999) combine motor vehicle emissions per mile data from a remote sensing experiment in California with vehicle mileage data by household obtained from the NHTS to study the replacement of existing vehicle registration fees by taxes on total yearly emissions, emissions per mile, and vehicle miles traveled. ${ }^{16}$ The authors construct a measure of lifetime income for each household in their dataset using a relationship between education and demographic data and lifetime income estimated earlier by Rogers (1993).

They find that, regardless of whether annual or lifetime income is used, the tax on emissions per mile is more regressive than the emissions tax, which in turn is more regressive than the tax on miles driven; this is because ownership of older, dirtier vehicles with higher emission rates is disproportionately concentrated among lower income households. They also find that the mileage tax looks more regressive than existing registration fees, which are based on vehicle value, on an annual income basis, though not on a lifetime income basis; this is because the mileage/income relation is weaker than the vehicle value/income relation on an annual basis, but this difference disappears under the lifetime income measure. Finally, adverse distributional effects of any of the three new taxes are diminished if revenues raised are used to reduce existing registration fees, which are themselves regressive.

West (2004a) integrates behavioral responses into an incidence analysis of motor vehicle taxes and subsidies based on an econometric model of household vehicle choice and mileage estimated with

\footnotetext{
${ }^{16}$ In principle, the emissions tax is the most efficient one, as it encourages abatement measures to reduce emissions per unit of fuel, improvements in fuel economy, and reduced driving. The other two taxes do not optimally exploit all of these behavioral responses. Emission taxes could be implemented based on data collected during periodic emissions rate inspections, and mileage data collected during the same inspection, or on a continuous basis via Global Positioning Systems. Ideally, an emissions tax would also vary by location, time of day, and temperature, as all these factors influence marginal pollution damages. At the present time, it is probably still impractical to implement a perfect emissions tax.
} 
CES data. The policies she considers are a tax on vehicle size, a mileage tax, and a subsidy to vehicle "newness." She finds that households in the lower income deciles have more elastic demands for miles traveled than those in the higher income deciles. Consequently looking at estimated tax payments as a share of lifetime income (proxied by annual consumption), without considering behavioral responses overstates the true regressivity of a mileage tax (see above). West finds, however, that the mileage tax is still regressive, even after accounting for behavioral responses. Interestingly, the tax payments as a share of income, or consumer surplus change as a share of income, become larger from the lowest decile to the middle deciles, but then fall after that, and drop sharply for the top decile. Some of this impact is due to low-income households who do not own a vehicle: the regressivity of the tax is greater when only households who own vehicles are considered. Finally, West also finds that both the subsidy for new vehicles and a tax on vehicle size are significantly regressive, more so than the mileage tax. ${ }^{17}$

\subsection{Emissions Permits}

Dinan and Rogers (2002) provided the first major contribution on the incidence of emissions permits; they considered a program to reduce US carbon emissions by 15\% below 1998 levels (at a permit price of $\$ 100$ per ton of carbon). They extend the modeling framework of Casler and Rafiqui (1993) to incorporate behavioral responses (assumed uniform across households), indexing of transfer payments (e.g., social security), and they allocate to households additional burdens from the effect of higher product prices on reducing real factor returns and compounding efficiency costs of pre-existing factor tax distortions (e.g., Goulder et al. 1999).

Dinan and Rogers' results show that distributional effects hinge crucially on whether permits are grandfathered or auctioned, and whether revenues from permit auctions, or from indirect taxation of permit rents, are used to cut payroll taxes, corporate taxes, or provide lump-sum transfers. For example, they estimate that households in the lowest income quintile would be worse off by around $\$ 500$ per year under grandfathered permits while, due to large indirect increases in the value of their stockholdings, households in the top income quintile would be better off by around $\$ 1,000$. If instead the permits were auctioned with revenues returned in equal lump-sum rebates for all households, they estimate that lowincome households would on net be better off by around $\$ 300$ while high-income households would be worse off by around $\$ 1,700 .^{18}$

\footnotetext{
${ }^{17}$ In a related study, West (2004b) analyzes the same taxes as Walls and Hanson (1999), but integrates differential behavioral responses across households. Results are broadly consistent with earlier ones, though the degree of regressivity is mitigated somewhat because lower income households are more price responsive than upper income households.

${ }^{18}$ On the other hand they find auctioned carbon permits to be regressive if revenues are used to cut payroll taxes, and highly regressive if they are used to cut corporate taxes.
} 
Parry (2004) estimates a simple, calibrated, analytical model with household income proxied by consumption to examine the incidence of emissions permits, among other control instruments, to control power plant emissions of $\mathrm{SO}_{2}$, carbon, and $\mathrm{NO}_{\mathrm{x}}$. He finds that using grandfathered emissions permits to reduce carbon emissions by $10 \%$, and $\mathrm{NO}_{\mathrm{x}}$ emissions by $30 \%$, can be highly regressive; the top income quintile is made better off while the bottom income quintile is made much worse off. The $\mathrm{SO}_{2}$ cap imposed by the 1990 Clean Air Act Amendments, which has reduced emissions by roughly 45\%, is also regressive but much less so than the carbon and $\mathrm{NO}_{\mathrm{x}}$ policies. This result underscores the point that permit rent relative to abatement costs, and hence the relative transfer to wealthy households, is smaller at higher levels of emission reductions.

Rose and Oladosu (2002) use a computable general equilibrium model with 41 production sectors, four factors of production, and 10 income brackets, to analyze a carbon permit trading system that reduces US emissions by 7\% below 1990 levels (the original US target under the Kyoto Treaty) for a permit price of \$128 per ton. With auctioned permits, and prior to revenue recycling, the lowest income bracket experiences a burden to income ratio 73\% larger than that for the top income bracket, reflecting the formers' larger budget shares for energy goods. When revenues are returned in income tax cuts, the policy is approximately proportional overall (burden to income ratios are similar across different households).

\subsection{Command and Control Regulations}

We now turn to some older literature on the incidence of US federal pollution regulations, which have historically been command and control programs. These older studies do not consider behavioral responses, and measure income on an annual rather than lifetime basis, so they likely overstate the degree of regressivity. Unlike literature discussed above, some of these older studies considered both policy benefits and costs; we discuss benefit estimates in the next section.

Dorfman and Snow (1975) looked at the costs of pollution controls incurred as a result of all federal environmental programs, by government, industry, and households. Government control costs are assumed to cause proportional increases in income taxes paid by households; industry costs are assumed to be fully passed forward in final product prices and are allocated to households based on their total consumption expenditures; and household pollution control costs are higher prices for vehicles resulting from emissions regulations, allocated on the basis of vehicle ownership. The study found the aggregate costs of federal regulations to be regressive with burden to income ratios of roughly $2 \%$ and $1 \%$ for the bottom and top income quintiles respectively. A major factor was that emissions standards drive up the price of lower-cost vehicles, purchased by poor households, by about the same amount in absolute terms 
as expensive ones, purchased by wealthy households; added costs relative to income are therefore greater for low-income households. ${ }^{19}$ However, in a similar study confined to the 1970 Clean Air Act, Giannessi et al. (1979) find a more complex incidence pattern when smaller household groups are disaggregated. They estimate that the bottom income decile incurs a lower burden to income ratio than other groups, as they had the lowest vehicle ownership rate. ${ }^{20}$

A drawback of these early studies is that they match total abatement costs to total consumption spending by households. Robison (1985) improves on this by matching estimates of price increases for 78 consumption goods with spending on these goods by household class; price increases are obtained using input-output tables and abatement costs (for all media) from the Pollution Abatement Costs and Expenditures (PACE) data. Results show that the regulations imposed on industry are regressive: the poorest $5 \%$ of the population paid about $1 \%$ of their income for such costs, the next $5 \%$ of the population paid about $0.6 \%$ of their income, with the burden continually declining to the richest $5 \%$, which paid only about $0.2 \%$ of their income.

Lake et al. (1979) examine costs of the 1972 Clean Water Act. They conduct an extensive analysis of the implied burden on households from different mechanisms for financing municipality water treatment expenses (taxes, sewer fees, bond issues, etc.). Overall costs of municipal wastewater treatment remain regressive, despite the federal grant program: the lowest income decile’s burden to income ratio is 3 times that for the highest income decile. Lake et al. also analyze control costs for ten final industries with high levels of wastewater discharge, and assign these costs to households based on their consumption patterns. Control costs are highly regressive: burden to income ratios are $2.4 \%$ and $0.13 \%$ respectively for the bottom and top income decile.

Collins (1977) also analyzes the federal grant program embodied in the Clean Water Act, focusing on a region in the Midwest rather than the whole nation. He estimates the amount and distribution of both the subsidies, and the implied tax increases, by income class. He finds that the highest income category benefits the most from the grant program and that middle-income groups incur the greatest cost; the lowest income groups get a slight positive benefit. High-income groups benefit primarily because of the implied subsidies to polluting firms. Ostro (1981) replicates Collins' work for the Boston metropolitan area, but obtains opposite results. In particular, he finds that all of the lower and

\footnotetext{
${ }^{19}$ These findings are similar to those in an earlier study by Harrison (1975), though that study looked at only vehicle emissions regulations, and also accounted for tax effects and stockholder burdens from reduced profits for vehicle manufacturers. Harrison estimated burden to income ratios of $1.5 \%$ for the lowest income quintile and $0.8 \%$ for the top income quintile.

${ }^{20}$ Consistent with Dorfman and Snow, other groups in the lower half of the income distribution suffered a burden to income ratio about double that of deciles in the upper half of the distribution.
} 
middle-income groups benefit from the grant program and the top four income groups lose. These findings are a result of assuming that the municipal subsidy accrues to groups in proportion to their water usage and population and a larger number of people are in the lower-to-middle income groups than the higher income groups. The author speculates that similar results might be found for other urban areas. ${ }^{21}$

For a number of reasons it would be useful to update and refine the type of analysis in these earlier, comprehensive studies of federal environmental regulations. In the last 25 years or more the income distribution has become more unequal, household expenditure patterns have changed, firms have often found new, radically more efficient ways to reduce pollution, and new laws and regulations have imposed new costs. In addition, limitations on the earlier work can be overcome; for example, using recent data, we can more accurately estimate lifetime income for various demographic groups, based on their current income, educational attainment, and age.

\subsection{Comparison Across Instruments}

Studies have generally focused on one policy instrument in isolation, rather than considering a broad range of alternative instruments. One exception is Parry (2004) who finds that the burden imposed on low-income households from control of power plant emissions can be lower under performance standards and technology mandates than under grandfathered permits (assuming homogeneous firms). For a given emissions reduction, the command-and-control policies cause higher abatement costs than emission permits as they fail to optimally exploit all the different margins for emission reductions; however, the overall product price increase is larger under emission permits, as it also reflects the large rents created under the policy. More research is needed on how robust this result might be to incorporating heterogeneity in abatement costs among firms, different levels of pollution reduction, noncompetitive pricing in the electricity sector, and other factors.

\subsection{Summary}

Most empirical studies find that the costs of environmental policies are borne disproportionately by lower income groups. This appears to hold across a range of policy instruments, especially

\footnotetext{
${ }^{21}$ There is a very small literature on incidence effects of energy efficiency standards for home appliances (e.g., refrigerators, washers, dryers), and demand-side management programs. Sutherland (1991) argued that there is a positive net burden from appliance standards (higher product prices exceed discounted savings from improved energy efficiency) and that the burden is borne disproportionately by poorer households. However, according to estimates by Stoft (1993) the net burden of a given standard is quantitatively very small. Sutherland (1994) finds that wealthier households are more likely to participate in voluntary utility demand-side management programs (e.g., home energy audits, rebates for the purchase of energy efficient) but that such programs do not significantly reduce electricity consumption. He speculates that the higher income households who participate are probably being subsidized to undertake conservation measures that they would take anyway, suggesting such programs have regressive effects.
} 
grandfathered emissions permits, though the bulk of empirical work has focused on taxes, particularly, energy taxes. The finding is less pronounced for taxes on intermediate products than for taxes on final goods, and when some measure of lifetime income is used rather than annual income, though measuring lifetime income remains problematic especially in cross-section studies. Perhaps the most important finding, and one that deserves more attention in future research, is the potential for revenue recycling (from taxes and auctioned permits) to mitigate the burden on low-income households. More attention should also be paid to the extent to which the burden of environmental policies is passed backwards in reduced returns to owners of capital, rather than forward to consumers in higher product prices.

\section{WHO BENEFITS FROM ENVIRONMENTAL POLICIES?}

An abundant "environmental justice" literature examines the distribution of existing environmental risks, but we should be cautious about using findings from this literature to make inferences about the distribution of welfare gains from policy, for at least four reasons. First, due to a lack of data, the bulk of the environmental justice literature uses measures of environmental risk that do not adequately account for the degree of exposure and factors affecting individuals' susceptibility to pollution-induced illness. Second, when policies create non-uniform environmental improvements, the existing risk distribution will inaccurately predict distributional benefits from the policy change. Third, to translate physical benefits into welfare gains we need to measure how different households value environmental quality. Finally, we also need to account for the possible effect of changing environmental quality on market prices or wages, as these price changes also affect household welfare. All of these issues are taken up in this section.

\subsection{Evidence on the Distribution of Prevailing Environmental Risks}

Studies have evaluated the existing distribution of environmental risks for many different pollutants at many different geographical scales. They merge data on environmental conditions with census data on the characteristics of local populations. ${ }^{22}$

\footnotetext{
${ }^{22}$ Initially, studies used convenient but approximate measures of affected populations, such as counties or postal codes. As techniques for working with geographic information became more sophisticated, researchers were able to measure the population residing within certain distances from pollution sources or monitoring stations. However tradeoffs arise in the choice of spatial scales (Bowen 2002): with smaller geographical units localized inequities are less likely to be overlooked, but measures of individuals' overall exposure may be less reliable. For example, an individual may work near a polluting facility and have considerable exposure, but live in a distant area and therefore be treated as having minimal exposure.
} 


\subsubsection{Findings}

Empirical literature on the distribution of existing environmental risks is so large that it is difficult to do justice to the range of methods and results. The discussion here is necessarily cursory because of the broader focus of this article and the availability of several comprehensive surveys (Bowen 2002, Pearce 2003, Hamilton 2005, and Ringquist 2005). Early studies, which focused mainly on air pollution in the United States, generally found a negative association between environmental risk and income (e.g., Freeman 1972, Zupan 1973, Asch and Seneca 1978, Harrison and Rubinfeld 1978). In the 1980s, studies also began to focus on waste management facilities and, in the 1990s, on toxic releases, using newly available data from the Toxic Release Inventory (TRI). Most of these studies also find that lower income groups suffer more exposure to hazardous waste management facilities (e.g., Hamilton 1993 and 1995, Yandle and Burton 1996) and to toxic releases (e.g., Brooks and Sethi 1997, Arora and Cason 1999, Ash and Fetter 2004).

However, the negative relation between income and environmental risk is not a universal finding. For example, Anderton et al. (1994) report no link between poverty rates and the location of waste management facilities in US cities and Harrison and Antweiler (2003) do not find an association between income and pollution releases in Canada. Ringquist (2005) conducts a meta-analysis to identify the sources of differences in the results; he finds that studies report a more negative association with income when they focus on the location of facilities, rather than the level of pollution, and a greater association with poverty when the exposure area is narrowly defined. In addition, as research has progressed, it has evolved from descriptive studies into causal analyses of the distribution of pollution. ${ }^{23}$ When studies report no effect of income, they may not mean no unconditional correlation between environmental risk and income, but lack of an additional effect beyond the effects of race, population density, education levels, etc. For incidence analysis, however, we may care about the unconditional relationship.

Literature on other countries is sparse. Pearce (2003) concludes that "while the evidence is very limited, the data for the United Kingdom suggest that the existing distribution of risks is biased towards the poor (p. 23)." Hamilton (2005) provides a detailed survey of studies from the United States and other OECD countries with a focus on risks from hazardous waste, toxic chemical releases, and contaminated sites. As in the United States, the studies he surveys mostly find greater pollution in poor neighborhoods, but exceptions arise.

\footnotetext{
${ }^{23}$ For example, Been (1997) and Wolverton (2002) look at the siting of new facilities (hazardous waste facilities and TRI facilities, respectively) to distinguish inequities in the siting process from the decision of households to move near facilities. They both find that poor neighborhoods are less likely to host new facilities.
} 


\subsubsection{Measures of environmental quality}

An important concern with this literature is whether environmental quality is appropriately measured. With a slight modification from Pearce (2003), consider a hierarchy of measures where each level builds on the previous one: (i) existence of a polluting facility, (ii) emissions of pollutants, (iii) ambient concentrations, (iv) exposure (which depends on ambient concentrations as filtered through an individual's behavior), and (v) personal risk (which depends on exposure as well as personal characteristics such as age and prior health status).

Unfortunately, exposure and personal risk are not directly observed, and therefore most studies use measures (i), (ii), or (iii). Existence of a polluting facility is obviously not an ideal measure of emissions, and local emissions may differ greatly from ambient pollution because of the timing of releases, possible import/export of emissions from/to neighboring regions, and factors such as topography and wind that affect dispersion rates. In the past, concentration data was limited to the small number of air pollutants for which a sizable monitoring network is available; more recently, ambient measures have been simulated by running emissions data through dispersion models (e.g., Shadbegian et al. 2004, Ash and Fetter 2004). However, a casual examination of the empirical literature suggests that the choice of emissions versus concentration does not affect the association between environmental risks and income, because neither measure depends on characteristics of exposed individuals.

In contrast, the difference between (iii) and (iv) may well skew the results because rich and poor households likely differ in their intentional and unintentional averting behavior. For example, low-income individuals may face greater risks from proximity to groundwater contamination because they are less likely to use filters or bottled water and may have more exposure to air pollution if they are more likely to work in outdoor occupations, such as construction. The distinction between (iv) and (v) may also be important because health status, and hence susceptibility to pollution-induced illness, bears a close relationship to income. ${ }^{24}$ Thus, the widespread practice of using measures (i) to (iii) instead of (iv) or (v) might lead to serious understatement of the income/risk association.

A few studies do work with measures of exposure or personal risk. For example, Brajer and Hall (1992) find a correlation between income and exposure, where the latter is measured by combining pollution data with a behavioral model of time spent in various indoor and outdoor activities. Hamilton and Viscusi (1999) find elevated cancer risks for minorities from contaminated sites to be cleaned up under the Superfund program, using EPA risk measures that depend in part on behavior (they do not

\footnotetext{
${ }^{24}$ For example, asthma, which greatly increases risk from air pollution, is much more prevalent in lower income individuals; a recent survey in the United States found adult asthma frequency of $9.8 \%$ among persons with family incomes of less than $\$ 15,000$ relative to only $5.9 \%$ among persons with family incomes of greater than $\$ 75,000$ (CDC 2001).
} 
report risks by income class). However, the quality of the risk measures in these types of studies depends critically on the accuracy of the behavioral modeling; more econometric work on such behaviors is needed.

\subsection{Evidence on the Distribution of Improvements from Environmental Policies}

Even if lower income households are disproportionately exposed to existing environmental risks, appropriately measured, they may not benefit disproportionately from environmental policies if the resulting environmental improvements are non-uniform. A limited number of empirical studies have addressed the distribution of improvements from pollution control policies. One difficulty in this literature is that the researcher needs to assume a counterfactual scenario representing what would have happened in the absence of policy change. This problem has been handled in a wide variety of ways.

One approach is to focus on changes in environmental quality over time that might be largely associated with policies. For example, Kahn (2001) examines changes in air quality at monitoring stations in the Los Angeles basin and finds that improvements have been greater in low-income census tracts. Such comparisons effectively assume that, without policy intervention, pollution would be unchanged. The implication of this assumption for the distribution of policy effects is unclear. For example, if pollution would have grown worse without policy intervention, it might have exacerbated inequality in existing risks; however, worsening pollution might also have spread the risks to relatively clean (and wealthy) neighborhoods.

A second approach is to simulate policy effects through some more sophisticated counterfactual. For example, Shadbegian et al. (2004) examine the distribution of benefits (and costs) of the US $\mathrm{SO}_{2}$ allowance-trading program. They compare the actual pattern of emissions in 1995 to a "without policy" baseline that applies a utility's emissions rate before the policy (1993) to its output with the policy (1995). They find that the poor received per capita benefits that were $5 \%$ lower than the average benefits over the whole population: that is, the distribution of ambient concentration reductions was slightly regressive.

A third approach is to examine the intensity of regulatory effort. Hamilton and Viscusi (1999) find some evidence of more aggressive policy responses for low-income communities in the Superfund program: target risk levels for cleanup are set lower (i.e., a more extensive cleanup is chosen) when the median income within 1 mile of the site is lower than average. This association may reflect behavioral assumptions-regulators could think that low-income residents practice less averting behavior and thus require more protection to achieve the same level of safety-but could also reflect special attention to low-income communities because of environmental equity concerns.

Gray and Shadebegian (2004) also study the intensity of regulatory effort, as measured by inspection and enforcement effort for air and water pollutants. They find that facilities with larger poor populations 
within 50 miles receive more frequent inspections and less frequent enforcement actions. Both these variables potentially measure plants' compliance, as well as the government's effort, and so are open to several interpretations. Nonetheless, a possibility is that the government devotes more attention to inspections near the poor and thus needs to devote less attention to enforcement, again supporting the view that government effort is progressively distributed.

\subsection{Relationship Between Environmental Improvements and Welfare}

Both the large environmental justice literature and the more limited literature on the distribution of policy improvements is focused almost entirely on environmental risks. However, changes in the pattern of environmental risks may give a misleading picture about changes the distribution of household welfare relative to income. This disparity between risks and welfare may arise because individuals may value risks differently and because they may be partly compensated for changes in risks via market price or wage adjustments.

4.3.1. Differential valuation of the environment. Most plausible forms of households' utility functions have willingness to pay (WTP) for environmental improvements that rise with income; ${ }^{25}$ however the implication of this positive relationship for the distribution of environmental benefits depends critically on the income elasticity of WTP for environmental improvements (Ebert, 2003). If this elasticity is greater than unity, the value of a uniform environmental improvement rises relative to income. Although a positive income elasticity seems extremely likely a priori, whether the elasticity is greater than one is an empirical issue. $^{26}$

Incidentally or intentionally, many studies provide information on this elasticity. Contingent valuation (CV) studies, which survey households on their WTP for specific environmental goods, often ask about income (among other household characteristics). In a survey of such studies in Europe, Kriström and Riera (1996) conclude that the income elasticity of WTP is positive but less than one; Hokby and Soderqvist (2003) find similar results from a review of CV studies for a range of environmental services in Sweden. Pearce (2003) argues that a range of .3 to .7 "seems about right” based his review of international CV studies.

${ }^{25}$ The use of WTP in estimating welfare impacts of policies for different income groups is routine among economists, although highly contentious outside of the economics profession (e.g., Heinzerling and Ackerman 2002). It raises conceptual concerns and political objections, especially when the environmental quality in question affects risks of death as it seems to imply that some people are "worth" more than others.

${ }^{26}$ A positive income elasticity of WTP is broadly consistent with the U-shaped relationship between environmental quality and per capita income estimated by some studies in the "Environmental Kuznets Curve" literature (Israel and Levinson 2004). 
A few revealed preference studies also measure income elasticities of WTP but reach highly conflicting results. For example, Sieg et al. (2004) estimate a general equilibrium model of property price changes in response to air quality improvements and find an income elasticity of WTP of more than 4 . In contrast, Boyle et al. (1999) find no association between the value of lake water clarity in Maine and income among the high-income households, suggesting a WTP elasticity of zero!

Another source of information on the income elasticity of WTP are the hedonic wage analyses and surveys used to value health risk reductions. Viscusi and Aldy (2003) summarize income elasticities from four previous meta-analyses of value of statistical life studies (Liu et al. 1997, Mrozek and Taylor 2002, Bowland and Beghin 2001, and Miller 2000) and then conduct their own meta-analysis on studies from 10 countries. Their preferred estimate for the income elasticity is $.46-.49 .{ }^{27}$

4.3.2. Market responses to environmental changes. Household welfare is also affected by changes in market prices that might accompany improvements in environmental quality. In particular, environmental improvements might be capitalized into housing prices or built into wages through wage premiums for workers with jobs in polluted areas (Roback 1982, Blomquist et al. 1988). ${ }^{28}$

Empirical evidence on capitalization in housing prices is widespread from the extensive literature on the hedonic valuation of environmental amenities (see for example a meta-analysis of studies of air pollution by Smith and Huang 1995). Chay and Greenstone (2005) find a substantial housing price effect from recent reductions in total suspended particulates, but also "a precisely estimated zero" effect on wages, suggesting that the housing market is the principal source of compensation for environmental improvements.

Property ownership is skewed toward well-off households; in the United States in 2003, 73\% of households above the poverty line owned homes, compared with $43 \%$ of households below it (US Census Bureau 2004, Table 964). These differences in ownership rates could have dramatic effects on the distribution of benefits. Households that own their home receive the benefit of any unanticipated environmental improvement that is fully capitalized, whereas households that rent may end up paying higher rental rates. In fact renters may even be made worse off on net if increased rental payments outweigh their valuation of the local environmental improvement. Evidence of relative out-migration of

\footnotetext{
${ }^{27}$ Valuations of illness are now beginning to supplement the large literature on death. For example, Dickie and Hubbel (2004) estimate an income elasticity of WTP to avoid acute respiratory disease of .5 based on survey data.

${ }^{28}$ One caveat is that housing prices (or wages) in areas unaffected by environmental quality improvements may also change; if dirty regions become cleaner, while clean regions are unaffected, the advantage of living in the latter areas are diminished and outward migration from them may lower their property values. Ideally, the distributional implications of these other price changes should also be taken into account.
} 
poorer families from areas of environmental improvements supports this possibility (e.g., Sieg, et al. 2004, Banzhaf and Walsh 2004), though migration only indicates harm for renters; when families that own homes leave, they take with them capital gains from the environmental improvement.

\subsection{Integrated cost and benefit studies}

Two older studies attempt to integrate cost and benefit distributions to study overall incidence. Gianessi et al. (1979) assume the benefits of the 1970 Clean Air Act are proportional to emissions reductions. ${ }^{29}$ Overall, they find benefits fall short of policy costs (discussed in Section 3 above) for all income groups, though the pattern of net losses is only mildly regressive. Dorfman (1977) integrated environmental benefits into the Dorfman and Snow (1975) cost analysis of all federal environmental regulations (see above), using a survey asking people whether they were willing to pay certain dollar amounts for "cleanup of the natural environment." The survey results indicated that wealthier people were willing to pay more relative to income; in fact, benefits exceeded costs for the top income quintile, but were less than costs for the bottom income quintile.

However, more recent aggregate (rather than distributional) studies find a much more favorable benefit-cost comparison for the Clean Air Act, due to stronger evidence on the link between pollution and health effects; this underscores the need for updating the earlier analyses.

\subsection{Summary}

Despite the extensive literature, the existing distribution of environmental risks is still controversial; many studies find that the poor face higher risks, but this result appears to be sensitive to the nature of the risk studied, with more recent studies chipping away at this as stylized fact. However, if exposure and health sensitivity considerations were adequately considered, it would likely tilt existing risks toward the poor.

But even if the poor disproportionately bear environmental risks, it does not necessarily follow that environmental policies have progressive benefits. Although there are some cases where actual policies have tended to skew benefits toward the poor (e.g., Superfund), this finding does not apply in other cases (e.g., the $\mathrm{SO}_{2}$ trading program)

Translating environmental improvements into welfare further muddies the picture. On the one hand, most available evidence suggests an income elasticity of WTP below unity, implying that the same

\footnotetext{
${ }^{29}$ Benefit estimates come from an earlier study where national estimates were allocated to local areas based on an index that accounted for local pollution, the population at risk, and land areas. Local pollution was estimated based on information about industrial activity, vehicle ownership, and home heating.
} 
emissions reduction for rich and poor households would represent a larger share of the poor households' income. On the other hand, capitalization of environmental improvements into housing values may disproportionately reduce benefits to low-income households. Much work remains to be done on all of these issues.

\section{INCORPORATING DISTRIBUTIONAL CONSIDERATIONS INTO ENVIRONMENTAL COST/BENEFIT ANALYSIS}

The standard practice among environmental economists — as in other fields of economics - is to keep efficiency and distributional issues separate. Very few cost-benefit analyses include more than a cursory mention of distribution, while incidence studies often ignore efficiency. There are often important methodological reasons for this separation, because models or approaches that work well for efficiency analysis can be completely inadequate for equity analysis, and vice-versa. ${ }^{30}$ And if the question is simply whether or not to implement a new regulation or tax, this decoupled approach can work well; policymakers can evaluate evidence on the aggregate net benefit and on distributional effects from different studies, and decide for themselves what weight to put on each. But this approach is inadequate in other cases; for example, in order to judge the optimal stringency of a particular policy intervention one must either ignore distribution entirely, or utilize an approach that integrates efficiency and equity. ${ }^{31}$

Below, we discuss three such approaches: using a social welfare function or set of distributional weights; imposing constraints on the losses that can be imposed on particular groups; and using “distribution-neutral” analysis.

\subsection{Social Welfare Function/Distributional Weights}

This approach allows the value of a dollar of benefits or costs to vary based on who receives that benefits or bears that cost. One way to do this is to evaluate policy based on how it affects social welfare,

\footnotetext{
${ }^{30}$ Aggregate time-series data sets, for example, can be sufficient for efficiency analysis, but do not include the information needed to measure distributional effects. Similarly, distributional analyses often ignore quantity responses to price changes, which are key to estimating efficiency effects.

${ }^{31}$ Studies that ignore distribution often justify this as an implementation of the Kaldor-Hicks criterion; if a policy passes an unweighted cost-benefit test, then it represents a potential Pareto improvement, because those who benefit from the policy could compensate those who lose. But whether the policy improves overall social welfare will also depend on its distributional effects.

It is often argued that environmental policy should not consider distribution, but should focus exclusively on efficiency, because tax and transfer policy is a much more direct way to achieve distributional goals. But redistribution through taxation of labor and capital, and means-tested benefits, has limits because it involves efficiency costs. To the extent that equity goals are not fully addressed through the tax and benefit system, the distributional effects of environmental policies remain a concern.
} 
which is a function of the utility of each individual (i.e., social welfare is given by the function $W\left(U_{1}, U_{2}, U_{3}\right)$, where $U_{i}$ is utility for individual $\left.i\right)$. Under this approach, concavity with respect to income in either the individual utility functions (i.e., decreasing marginal utility per dollar of income), or in the social welfare function (i.e., decreasing marginal social welfare per util) causes the marginal social welfare per dollar for any given individual to be decreasing in that individual's income.

A simplified version of this approach assigns a "distributional weight” for each individual, and then calculates the weighted sum of costs and benefits. ${ }^{32}$ Distributional weights (or values for marginal social welfare per dollar) that decrease with income imply that society cares about equity as well as efficiency. It is common to set these weights using an isoelastic function, which implies that the weight on individual $i$ is equal to $(1-\varepsilon)^{-1} \Sigma_{i}\left(Y_{i}^{1-\varepsilon} / \bar{Y}^{-\varepsilon}\right)$, where $\bar{Y}$ is mean income and $\varepsilon$ represents society's aversion to inequality. For $\varepsilon=0$, the weights are constant, equivalent to an unweighted cost-benefit measure; $\varepsilon=1$ gives weights inversely proportional to income; and $\varepsilon=\infty$ implies zero weight on all but the very poorest individual. ${ }^{33}$

This approach is only slightly more complex than standard (unweighted) cost-benefit analysis; the social welfare function looks much like an individual utility function, and thus the intuition and techniques developed for consumer utility maximization translate easily into social welfare maximization. And the distributional weights have an obvious and intuitive interpretation. Recent environmental applications of this approach include Fankhauser et al. (1997) on the aggregation of projected climate change damages across rich and poor nations; Mayeres (2001) on various transportation policies; Parry (2004) on the social costs of emissions permits; and literature on optimal environmental taxes with heterogeneous agents (e.g., Cremer et al. 1998 and 2003, Eskeland 2000, Mayeres and Proost 1997 and 2001, and Pirttilä and Tuomala 1997).

The major difficulty, of course, comes in determining what set of distributional weights to use. The choice of weights can have a dramatic effect on the magnitude of the change in social welfare, and can even alter the sign of that change. One method, analogous to using revealed preference to infer individual utility functions, is to infer distributional weights based on the tradeoffs made in other

\footnotetext{
${ }^{32}$ Note that this weighted cost-benefit measure provides a first-order approximation to the change in social welfare if the distributional weight on any given individual equals the marginal social welfare per dollar of income (i.e., if the weight for individual $i$ equals $\left(\partial W / \partial U_{i}\right)\left(\partial U_{i} / \partial Y_{i}\right)$, where $Y_{i}$ is that individual's income).

${ }^{33}$ These weights approximate an isoelastic social welfare function if utility is roughly proportional to income. In this case, $\varepsilon=0$ implies a utilitarian social welfare function, while $\varepsilon=\infty$ implies a Rawlsian social welfare function (Atkinson and Stiglitz 1980, pp. 340).
} 
government decisions. ${ }^{34}$ However, these estimates may be an unreliable indicator of society's true preferences, because policy decisions are not strictly the result of benevolent optimization, but are determined at least in part by the interplay of powerful interest groups.

Alternatively, a set of weights could be chosen that appear reasonable, but that choice is inherently arbitrary, and may lead to the acceptance of policies that would perform very badly on an unweighted cost/benefit analysis (e.g., Harberger 1976). One possible response to this problem is to consider a range of different social welfare functions (e.g., by varying the inequality aversion parameter), and look for robust qualitative results (e.g., instrument A always yields greater social welfare than instrument B). But such robust results may not exist, and there is little consensus over the appropriate range of social welfare functions to consider. ${ }^{35}$

\subsection{Distributional Constraints}

This approach uses an unweighted cost-benefit measure, but rules out policies that would make particular groups worse off. For example, when evaluating an automobile emissions testing program, one might impose the constraint that low-income households cannot be made worse off. This would rule out a policy that simply imposes a stringent emissions limitation, because many older cars owned by lowincome households would fail that test. Some real-world testing programs satisfy this distributional constraint by exempting low-income households. But a more efficient way to satisfy the constraint would be for the government to offer to buy back those older cars, rather than simply banning them, or to compensate low-income households in some other way (such as with a tax credit).

We are not aware of any environmental study that explicitly incorporates distributional constraints based on household income. But some studies do impose other distributional constraints. For example, recent papers by Bovenberg and Goulder (2001) and Bovenberg et al. (2004) examine pollution control costs under the constraint that profits of particular industries do not fall. The rationale for that constraint is that politically powerful industries could block any policy that would make them worse off. In these studies, politically powerful industries are still subject to emissions controls, but they receive compensation through rents obtained from the allocation of free emission permits

\footnotetext{
${ }^{34}$ For example, Gruber and Saez (2002) calculate a set of distributional weights that are consistent with the efficiency cost of raising income tax revenue from different income groups. It is not always possible to solve this "inverse optimum problem"; for example, Ahmad and Stern (1984) could not find a positive set of weights that might justify the commodity tax system in India, which implies that commodity tax reform could make all income groups better off.

${ }^{35}$ For example, Parry (2004) uses values of $0,0.5$, and 1 for the inequality aversion parameter $\varepsilon$, Cremer at al. (1998) uses 0.1 and 1.9, and Fankhauser et al. (1997) uses 0, 1, and $\infty$.
} 
Distributional constraints are straightforward to implement, as long as the set of constraints is not overly complex. But the choice of constraints will typically be somewhat arbitrary. Bovenberg and Goulder's (2001) analysis, for example, imposes the constraint that utilities and fossil fuel producers cannot suffer a net loss from policies to reduce carbon emissions, but imposes no such constraint on other industries or consumer groups.

Another problem is that satisfying the distributional constraints could potentially be very costly in terms of economic efficiency. In theory, distributional constraints could lead to the rejection of policies that generate tiny losses for a favored group, even if they produce huge benefits for other (non-favored) groups. A more practical example is the policy mentioned above that exempts low-income households from auto emissions testing. This policy is inefficient because it fails to exploit potential reductions in emissions from those households' cars that, in the absence of distributional concerns, would probably be the most cost-effective reductions available. And in the Bovenberg and Goulder and Bovenberg et al. papers efficiency losses result because compensation schemes erode the amount of government revenue collected from auctioned permits (or emission taxes) that can be used to finance cuts in other distortionary taxes. Moreover, in these studies the fraction of permits (or of emissions tax revenue) that must be used for compensation increases with the level of abatement; indeed, beyond a certain reduction in emissions, full compensation becomes infeasible.

\subsection{Distribution-Neutral Analysis}

The distribution-neutral approach evaluates a particular policy by creating a hypothetical "neutralized" version of that policy—one with no distributional effects—and seeing if that policy passes a cost-benefit test. As proposed by Kaplow (1996, 2004), this entails two steps. The first is to calculate what changes to the income tax schedule would exactly compensate each income group for the effects of the policy, thereby neutralizing the distributional effects of the policy. This would require a compensating income tax cut for any income group that would suffer a loss from the policy, and a compensating tax increase for any group that would receive a gain. Thus, the combination of the policy in question and the compensating changes in the tax schedule would leave each income group no better or worse off than in the status quo. The second step is to estimate whether that combination-the policy in question plus the compensating income tax changes — would increase or decrease net government revenue. If it would increase net revenue, then it is possible to make all income groups better off (by distributing the excess revenue as a lump-sum transfer). But if it would decrease net revenue, then the opposite result holds: the 
government could not possibly compensate everyone who is made worse off by the policy, even if it were to tax away all of the gains from those who benefit from the policy. ${ }^{36}$

Williams (2004) provides the first empirical application of this approach, using it to calculate the optimal gasoline tax. The gasoline tax is regressive, so neutralizing its distributional effects requires making the income tax schedule more progressive, which has an efficiency cost. ${ }^{37}$ Consequently, the distribution-neutral approach yields a lower optimal gasoline tax rate (which Williams estimates at \$0.91 per gallon in 1997 dollars) that is lower than the efficiency-maximizing tax rate (estimated at \$1.03 per gallon).

Thus, this approach provides a way to bring distributional considerations into cost-benefit analysis, while still avoiding the problems inherent in the previous two approaches. It is similar in concept to the Hicks-Kaldor criterion in that it looks for a potential Pareto improvement, but it accounts for the efficiency costs of redistribution, whereas the Hicks-Kaldor criterion implicitly assumes that redistribution is costless.

However, just because the income tax schedule could be adjusted to prevent anyone being made worse off doesn't necessarily mean that it will be (of course, the same criticism applies to Hicks-Kaldor). A more serious problem is that the compensation might not even be possible; if there is heterogeneity within an income group, such that some people in this group gain from a policy while others lose, then the income tax cannot neutralize distributional effects within that group. ${ }^{38}$

Another potential problem is that distribution-neutral analysis can be complicated to implement when the welfare effects of a policy are a nonlinear function of income. The cost would be nonlinear if the income elasticity of demand for the polluting good varies across the income distribution (as is the case for gasoline, which has an income elasticity less than one over most of the income distribution, but greater than one near the bottom of the income distribution, where owning a car is a luxury). The environmental benefits are nonlinear if the income elasticity of WTP varies over the income distribution, or if exposure to a pollutant varies nonlinearly with income. In any of these cases, the hypothetical

\footnotetext{
${ }^{36}$ This approach implicitly takes into account the efficiency costs of redistribution, because the compensation comes not from individual-specific lump-sum taxes and transfers, but rather from changes in the income tax schedule, and thus may change the excess burden of the income tax.

${ }^{37}$ The compensating change in the income tax schedule depends on the distribution of benefits as well as the distribution of costs. However Williams (2004) assumes that the external benefits of lower gasoline consumption are proportional to income, so compensating for those benefits does not affect the progressivity of the income tax.

${ }^{38}$ This problem arises in Williams (2004), because at any given income level, some households use more gasoline than others, and bear more of the burden of increases in the gasoline tax. Thus, while the tax schedule can be adjusted so that for any level of income, the average household at that level is exactly compensated for the increased gasoline tax, this will undercompensate households that use more gasoline than the average for their income level, and will overcompensate those that use less than average.
} 
compensating change in the income tax schedule will also be nonlinear, and evaluating the efficiency effects of that compensating change will be complicated.

Surprisingly, Kaplow (2004) shows that distribution-neutral analysis yields the same result as one would get by ignoring both distributional effects and interactions with pre-existing tax distortions. Thus, he argues that imposing distribution neutrality might actually simplify cost-benefit analysis. However Williams (2005) shows that this result holds only under a restricted specification for utility, which is frequently rejected in empirical studies.

\subsection{Conclusions}

Given the drawbacks of each of these approaches, they should be used with caution. In most cases, it is better to provide separate measures of the efficiency and equity effects of a policy than to attempt to integrate them into a single measure. However there are some problems, such as calculating socially optimal policies, for which an integrated measure may be appropriate. In such cases, the best approach for a given problem will depend on the characteristics of the problem. If distributional effects matter primarily because of political concerns (i.e., imposing too heavy a burden on a particular group will cause that group to block the policy), then it is straightforward to represent those concerns as distributional constraints.

On the other hand, if distributional effects matter primarily for equity reasons, then using distributional weights or distribution-neutral analysis will likely be the best approaches. Because it does not rely on an arbitrary assumption about society's aversion to inequality, distribution-neutral analysis can provide the most rigorous and objective results, but only if it is applied without imposing unrealistic restrictions on preferences - and it can be very complicated to implement without those restrictions. Often, a simpler approach will be needed, and in such cases the best option is probably to use distributional weights based on an isoelastic function, and to consider a wide range of possible values for the inequality aversion parameter.

\section{LESSONS LEARNED AND TOPICS FOR FUTURE RESEARCH}

Although in general (with some exceptions) low-income households appear to bear a disproportionate share of existing environmental risks, policies that reduce environmental risks are not necessarily progressive. For example, the geographic pattern of emissions reductions may be uneven, and induced changes in property values may indirectly benefit the wealthy at the expense of the poor. Moreover, (again with some exceptions) the costs of environmental policies tend to fall most heavily on poorer groups through increases in product prices, as energy goods are necessities. And the type of emissions control instrument can be critically important; freely allocated tradable emission permits may 
actually hurt the poor the most, as they transfer income to shareholders via scarcity rents created at the expense of higher prices. On the other hand, emissions taxes (or auctioned emission permits) offer the opportunity to offset regressive effects, if revenues are recycled to finance progressive changes to the tax system.

Revenue-raising environmental policies have, however, proven extremely difficult to implement in the United States; recent legislation has instead favored grandfathered emissions permits where policy rents accrue to regulated firms. ${ }^{39}$ Although the chance of new environmental or energy taxes being introduced in the next few years appears very remote, it is conceivable that this situation may change further down the road, given continuing pressures to "do something” about US greenhouse gas emissions and looming deficit problems from retiring baby boomers.

Although literature on incidence of pollution control policies has been expanding rapidly in recent years, the above discussion reveals that existing analysis is very thin, or even non-existent, in a wide range of critical areas. We finish by summarizing a variety of topics in particular need of attention.

Empirical studies on the extent to which the costs of environmental policies are passed forward into higher prices of consumer products would be extremely valuable; at present, empirical analyses typically assume $100 \%$ pass-through based on the assumption of competitive, constant returns production. ${ }^{40}$ Also on the cost side, there is a need for more unifying analyses that compare the incidence of a broad range of alternative control instruments for a particular pollutant (taxes, permits, technology mandates, etc.) on a consistent basis. And how relative incidence effects of policies depend on factors such as the extent of pollution reduction, abatement cost heterogeneity among firms, changes in relative factor prices, non-competitive pricing, and differences in emissions intensity between marginal and inframarginal production, all need to be explored. This research effort would aid policymakers in gauging when the choice of instrument is important for distributional concerns and when it is not.

A related issue is the extent to which adverse distributional impacts might be offset via targeted tax reductions from the recycling of revenue raised from emissions taxes and auctioned permits. It would also be useful to examine the efficiency gains forgone by targeting tax reductions to specific income groups, in place of more broadly based tax reductions. Again, research on these issues would inform policymakers about the strength of the economic case for using revenue-raising policies in preference to grandfathered permit trading programs.

\footnotetext{
${ }^{39}$ The McCain/Lieberman bill to reduce carbon emissions, and recent EPA rulings to reduce utility emissions of $\mathrm{SO}_{2}, \mathrm{NO}_{\mathrm{X}}$ and mercury, would primarily grandfather permits to existing emission sources.

40 There is an empirical literature on the pass-through of taxes into consumer prices in contexts other than environmental policy (see Fullerton and Metcalf 2002, section 2.6).
} 
On the benefit side, research should address the distribution of physical environmental benefits from policy changes (as opposed to the existing distribution of environmental risks), ideally with account taken of how health effects depend on exposure and personal characteristics. And to quantify the pattern of welfare gains from environmental improvements, these estimates need to be merged with estimates of the willingness to pay for environmental quality across households, as well as estimates of potentially offsetting effects from price adjustments in housing markets.

Moreover, very few studies integrate both the benefit and cost side of particular environmental regulations, in order to obtain the distribution of overall welfare effects across household groups. The last comprehensive study of the incidence of federal environmental regulations uses data from the 1970s.

Finally, further development of alternative approaches for incorporating distributional considerations into cost/benefit analyses is needed. Many problems require an integrated analysis of efficiency and equity, but the choice of distributional weights or distributional constraints is arbitrary. Distribution-neutral analysis avoids that problem, but is difficult to implement except under very restrictive assumptions. Progress in this area-a less arbitrary means of determining distributional weights or constraints, a simpler and more general method for distribution-neutral analysis, or an entirely new approach altogether — would be very valuable.

\section{References}

Ahmad, Ehtisham and Nicholas Stern, 1984. “The Theory of Reform and Indian Indirect Taxes.” Journal of Public Economics 25: 259-298.

Anderton, Douglas L., Andy B. Anderson, John Michael Oakes, and Michael R. Fraser, 1994.

“Environmental Equity: The Demographics of Dumping.” Demography 31: 229-248.

Arora, Seema, and Timothy N. Cason, 1999. "Do Community Characteristics Influence Environmental Outcomes? Evidence from the Toxics Release Inventory.” Southern Economic Journal, 65: 691-716.

Asch, P. and J. Seneca, 1978. "Some Evidence on the Distribution of Air Quality.” Land Economics 54: 218-257.

Ash, Michael and T. Robert Fetter, 2004. "Who Lives on the Wrong Side of the Environmental Tracks? Evidence from the EPA's Risk-Screening Environmental Indicators Model.” Social Science Quarterly 85: 441-462.

Antweiler, Werner, Brian R. Copeland and M. Scott Taylor, 2001. "Is Free Trade Good for the Environment?” American Economic Review 91: 877-908.

Atkinson, Anthony B. and Joseph E. Stiglitz, 1980. Lectures on Public Economics. McGraw-Hill, New York. 
Azar, C. and Thomas Sterner, 1996. "Discounting and Distributional Considerations in the Context of Global Warming.” Ecological Economics 19: 169-184.

Banzhaf, H. Spencer and Randall P. Walsh, 2004. "Testing for Environmental Gentrification: Migratory Responses to Changes in Environmental Quality.” Working paper, Resources for the Future, Washington, DC.

Barthold, Thomas. 1994. “How Should We Measure Distribution?” National Tax Journal 46: 291-99.

Been, Vicki and Francis Gupta, 1997. "Coming to the Nuisance or Going to the Barrios: A Longitudinal Analysis of Environmental Justice Claims.” Ecological Law Quarterly 24: 1-56.

Bento, Antonio, Lawrence Goulder, Emeric Henry, Mark Jacobsen, and Roger von Haefen, 2005. "Distributional and Efficiency Impacts of Gasoline Taxes: An Econometrically-Based Multi-Market Study.” American Economic Review Papers and Proceedings, forthcoming.

Blomquist, Glenn C, Berger, Mark C \& Hoehn, John P, 1988. "New Estimates of Quality of Life in Urban Areas.” American Economic Review 78: 89-107.

Borenstein, Severin, James B. Bushnell and Frank A. Wolak, 2002. "Measuring Market Inefficiencies in California’s Restructured Wholesale Electricity Market.” American Economic Review 92: 1376-1405.

Bovenberg, A. Lans, and Lawrence H. Goulder, 2001. "Neutralizing the Adverse Industry Impacts of CO2 Abatement Policies: What Does It Cost?” In C. Carraro and G. Metcalf, eds., Behavioral and Distributional Effects of Environmental Policy, University of Chicago Press, Chicago.

Bovenberg, A. Lans, Lawrence H. Goulder, and Derek J. Gurney, 2004. "Efficiency Costs of Meeting Industry-Distributional Constraints under Environmental Permits and Taxes.” RAND Journal of Economics, forthcoming.

Bowen, William, 2002. "An Analytical Review of Environmental Justice Research: What do We Really Know?” Environmental Management 29: 3-15.

Bowland, Bradley J. and John C. Beghin, 2001. "Robust Estimates of Value of a Statistical Life for Developing Economies.” Journal of Policy Modeling 23: 385-396.

Boyle, Kevin J., P. Joan Poor, and Laura O. Taylor, 1999. "Estimating the Demand for Protecting Freshwater Lakes from Eutrophication.” American Journal of Agricultural Economics 81: 1118-22.

Brajer, Victor and Jane V. Hall, 1992. "Recent Evidence on the Distribution of Air Pollution Effects.” Contemporary Economic Policy 10: 63-71.

Brennan, Timothy J., Karen L. Palmer and Salvador A. Martinez, 2002. Alternating Currents: Electricity Markets and Public Policy. Resources for the Future, Washington, DC.

Brooks, Nancy, and Rejiv Sethi, 1997. "The Distribution of Pollution: Community Characteristics and Exposure to Air Toxics.” Journal of Environmental Economics and Management 32: 233-250.

Brännlund, Runar and Jonas Nordström, 2004. "Carbon Tax Simulations Using a Household Demand Model.” European Economic Review 48: 211-33. 
Bull, Nicholas, Kevin Hassett, and Gilbert Metcalf, 1994. "Who Pays Broad-Based Energy Taxes? Computing Lifetime and Regional Incidence.” The Energy Journal 15: 145-64.

Burtraw, Dallas, Karen L. Palmer, Ranjit Bharvirkar, and Anthony Paul, 2001. "The Effect of Allowance Allocation on the Cost of Carbon Emissions Trading.” Discussion paper 01-30, Resources for the Future, Washington, DC.

Carraro, Carlo (Ed.), 2000. Efficiency and Equity of Climate Change Policy. Kluwer Academic Publishers, Boston.

Casler, Stephen D. and Aisha Rafiqui, 1993. "Evaluating Fuel Tax Equity: Direct and Indirect Distributional Effects.” National Tax Journal 46: 197-205.

Casperson, Erik and Gilbert Metcalf, 1994. "Is a Value Added Tax Regressive? Annual Versus Lifetime Incidence Measures.” National Tax Journal XL VII: 731-747.

CDC, 2001. "Self-Reported Asthma Prevalence among Adults — United States, 2000.” Centers for Disease Control, Morbidity and Mortality Weekly Report 50: 682-6.

Chay, Kenneth and Michael Greenstone, 2005. "Does Air Quality Matter? Evidence from the Housing Market.” Journal of Political Economy 113: 376-424.

Collins, Robert, 1977. “The Distributive Effects of Public Law 92-500.” Journal of Environmental Economics and Management 4: 344-54.

Cornwell, Antonia and John Creedy, 1997. "Measuring the Welfare Effects of Tax Changes Using the LES: An Application to a Carbon Tax.” Empirical Economics 22: 589-613.

Cremer, Helmuth, Firouz Gahvari, and Norbert Ladoux, 1998. "Externalities and Optimal Taxation.” Journal of Public Economics 70: 343-364.

Cremer, Helmuth, Firouz Gahvari, and Norbert Ladoux, 2003. "Environmental Taxes with Heterogeneous Consumers: An Application to Energy Consumption in France.” Journal of Public Economics 87: 27912815.

Cropper, Maureeen L and Wallace E. Oates, 1992. “Environmental Economics: A Survey.” Journal of Economic Literature XXX: 675-740.

Dickie, Mark and Bryan Hubbell, 2004. "Family Resource Allocation and the Distribution of Health Benefits of Air Pollution Control.” Working paper, US Environmental Protection Agency, Washington, DC.

Dinan, Terry M. and Diane Lim Rogers, 2002. "Distributional Effects of Carbon Allowance Trading: How Government Decisions Determine Winners and Losers.” National Tax Journal LV: 199-222.

Dorfman, Robert, 1977. "Incidence of the Benefits and Costs of Environmental Programs.” American Economic Review 67: 333-340. 
Dorfman, Nancy S. and Arthur Snow, 1975. "Who Will Pay for Pollution Control? The Distribution by Income of the Burden of the National Environmental Protection Program, 1972-1980.” National Tax Journal XXVII: 101-115.

Ebert, Udo, 2003. "Environmental Goods and the Distribution of Income.” Environmental \& Resource Economics 25: 435-59.

EPA, 1996. National Air Quality and Emissions Trends Report 1995. US Environmental Protection Agency, Washington DC.

Eskeland, Gunnar, 2000. “Environmental Protection and Optimal Taxation.” Discussion paper, World Bank, Washington, DC.

Fankhauser, Samuel, Richard Tol, and David Pearce, 1997. "The Aggregation of Climate Change Damages: A Welfare Theoretic Approach.” Environmental and Resource Economics 10: 249-266.

Feitelson, Eran J., Robert E. Hurd, and Richard R. Mudge, 1996. "The Impact of Airport Noise on Willingness to Pay for Residences.” Transportation Research: Part D: Transport Environment 1: 1-14.

Freeman, A.Myrick, 1972. “The Distribution of Environmental Quality.” In Alan Kneese and Blair Bower (eds.), Environmental Quality Analysis, Johns Hopkins University Press, Baltimore, 243-80.

Fullerton, Don and Diane Lim Rogers, 1993. Who Bears the Lifetime Tax Burden? Brookings Institution, Washington, DC.

Fullerton, Don and Gilbert E. Metcalf, 2002. “Tax Incidence.” In A.J. Auerbach and M. Feldstein (eds.), Handbook of Public Economics 4, Elsevier, New York.

Fullerton, Don and Garth Heutel, 2004. “The General Equilibrium Incidence of Environmental Taxes.” Working paper, Department of Economics, University of Texas.

Fullerton, Don and Garth Heutel, 2005. “The General Equilibrium Incidence of Environmental Mandates.” Working paper, Department of Economics, University of Texas.

Gale, William, Scott Houser and J. Karl Scholz, 1996. "Distributional Effects of Fundamental Tax Reform.” In H. Aaron and W. Gale (eds.) Economic Effects of Fundamental Tax Reform, Brookings Institution, Washington, DC.

Gianessi, Leonard P., Henry M. Peskin and Edward N. Wolff, 1979. "The Distributional Effects of Uniform Air Pollution Policy in the United States.” Quarterly Journal of Economics 93: 281-301.

Goulder, Lawrence H., Ian W.H. Parry, Dallas Burtraw and Roberton C. Williams, 1999. "The CostEffectiveness of Alternative Instruments for Environmental Protection in a Second-Best Setting.” Journal of Public Economics 72: 329-360.

Gray, Wayne B. and Ronald J. Shadbegian, 2004. "Optimal Pollution Abatement-whose Benefits Matter, and How Much?” Journal of Environmental Economics and Management 47: 510-534.

Gruber, Jon and Emmanuel Saez, 2002. “The Elasticity of Taxable Income: Evidence and Implications.” Journal of Public Economics 84: 1-32. 
Hahn, Robert W., 2005. In Defense of the Economic Analysis of Regulation. AEI-Brookings Joint Center for Regulatory Studies, Washington, DC.

Hamilton, James T., 2005. "Environmental Equity and the Siting of Hazardous Waste Facilities in OECD Countries: Evidence and Policies.” In T. Tietenberg and H. Folmer (eds.), International Yearbook of Environmental and Resource Economics 2005/2006, Edward Elgar, Cheltenham, UK.

Hamilton, James T., and W. Kip Viscusi, 1999. Calculating Risks? The Spatial and Political Dimensions of Hazardous Waste Policy. MIT Press, Cambridge, MA.

Hamilton, James T., 1993. "Politics and Social Costs: Estimating the Impact of Collective Action on Hazardous Waste facilities.” RAND Journal of Economics 24: 101-125.

Hamilton, James T., 1995. “Testing for Environmental Racism: Prejudice, Profits, Political Power?” Journal of Policy Analysis and Management 14: 107-132.

Harberger, Arnold C., 1976. "On the Use of Distributional Weights in Social Cost-Benefit Analysis.” Journal of Political Economy 86: S87-S120.

Harrison, David, 1975. Who Pays for Clean Air? The Costs and Benefit Distribution of Automobile Emissions Standards. Ballinger, Cambridge, MA.

Harrison, David, Jr., and Daniel L. Rubinfeld, 1978. “The Distribution of Benefits from Improvements in Urban Air Quality” Journal of Environmental Economics \& Management 5: 313-32.

Harrison, Kathryn and Werner Antweiler, 2003. "Incentives for Pollution Abatement: Regulation, Regulatory Threats, and Nongovernmental Pressures.” Journal of Policy Analysis and Management 22: 361-382.

Heinzerling, Lisa and Frank Ackerman, 2002. Pricing the Priceless: Cost Benefit Analysis of Environmental Protection. Georgetown Environmental Law and Policy Institute, Georgetown University, Washington, DC.

Hokby Stina and Tore Soderqvist, 2003. "Elasticities of Demand and Willingness to Pay for Environmental Services in Sweden.” Environmental and Resource Economics 26: 361-383.

Israel, Debra and Arik Levinson, 2004. "Willingness to Pay for Environmental Quality: Testable Empirical Implications of the Growth and Environment Literature.” Contributions to Economic Analysis \& Policy 3: No. 1, Article 2.

Kahn, Matthew E., 2001. “Beneficiaries of Clean Air Act Legislation.” Regulation 24: 34-39.

Kaplow, Louis, 1996. “The Optimal Supply of Public Goods and the Distortionary Cost of Taxation.” National Tax Journal 49: 513-533.

Kaplow, Louis, 2004. "On the (Ir)relevance of Distribution and Labor Supply Distortion to Government Policy.” Journal of Economic Perspectives 18:159-175.

Kinnaman, Thomas C. and Donald Fullerton, 2000. "The Economics of Residential Solid Waste Management.” In Tom Tietenberg and Henk Folmer (eds.), International Yearbook of Environmental and Resource Economics 2000/2001, Edward Elgar, Cheltenham, UK. 
Kristrom, Bengt and Pere Riera, 1996. "Is the Income Elasticity of Environmental Improvements Less Than One?” Environmental \& Resource Economics 7: 45-55.

Lake, Elizabeth, William M. Hanneman, and Sharon Oster, 1979. Who Pays for Clean Water? The Distribution of Water Pollution Control Costs. Westview Press, Boulder, CO.

Liu, Jin Tan; Hammitt, James K.; Liu, Jin Long, 1997. "Estimating Hedonic Wage Function and Value of Life in a Developing Country.” Economics Letters 57: 353-358.

Mayeres, Inge, 2001. “Equity and Transport Policy Reform.” Discussion paper, Center for Economic Studies, K.U. Leuven, Belgium.

Mayeres, Inge and Stef Proost, 1997. "Optimal Tax and Public Investment Rules for Congestion Type of Externalities.” Scandinavian Journal of Economics 99: 261-279.

Mayeres, Inge and Stef Proost, 2001. "Marginal Tax Reform, Externalities, and Income Distribution.” Journal of Public Economics 79:343-363.

Metcalf, Gilbert E., 1994. "The Lifetime Incidence of State and Local Taxes: Measuring Changes During the 1980s.” In J. Slemrod (ed.), Tax Progressivity and Income Inequality. Cambridge University Press, Cambridge, MA.

Metcalf, Gilbert E., 1999. “A Distributional Analysis of Green Tax Reforms.” National Tax Journal 52: 665-681.

Miller, Ted R., 2000. "Variations between Countries in Values of Statistical Life,” Journal of Transport Economics and Policy 34: 169-188.

Morgenstern, Richard D., 1997. Economic Analyses at EPA: Assessing Regulatory Impact. Resources for the Future, Washington, DC.

Mrozek, Janusz R. and Laura O. Taylor, 2002. "What Determines the Value of Life? A Meta-Analysis.” Journal of Policy Analysis and Management 21: 253-270.

Ostro, Bart D. 1981. “The Distributive Effects of Public Law 92-500.” Journal of Environmental Economics and Management 8:196-198.

Parry, Ian W.H., 2004. “Are Emissions Permits Regressive?” Journal of Environmental Economics and Management 47: 364-387.

Parry, Ian W.H., 2005. "Fiscal Interactions and the Costs of Pollution Control from Electricity.” RAND Journal of Economics, forthcoming.

Pearce, David, 2003. "Conceptual Framework for Analyzing the Distributive Impacts of Environmental Policies.” Prepared for the OECD Environment Directorate Workshop on the Distribution of Benefits and Costs of Environmental Policies, Paris.

Pirttilä, Jukka and Matti Tuomala, 1997. "Income Tax, Commodity Tax and Environmental Policy.” International Tax and Public Finance 4: 379-393 
Portney, Paul R. and John P. Weyant (eds.), 1999. Discounting and Intergenerational Equity. Resources for the Future, Washington, DC.

Poterba, James M., 1989. "Lifetime Incidence and the Distributional Burden of Excise Taxes.” American Economic Review 79: 325-330.

Poterba, James M., 1991. “Is the Gasoline Tax Regressive?” In David Bradford (ed.), Tax Policy and the Economy 5. National Bureau of Economic Research, Cambridge, MA.

Ringquist, Evan J. 2005. “Assessing Evidence of Environmental Inequities: A Meta-Analysis.” Journal of Policy Analysis and Management 24: 223-247.

Roback, Jennifer, 1982. “Wages, Rents, and the Quality of Life.” Journal of Political Economy 90: 12571278.

Robison, H. David, 1985. “Who Pays for Industrial Pollution Abatement?” Review of Economics and Statistics 67: 702-706.

Rogers, Diane Lim, 1993. “Measuring the Distributional Effects of Corrective Taxation.” Paper presented at a National Tax Association session of the Allied Social Science Association Meetings, Boston, January 3-5.

Rose, Adam and Gbadebo Oladosu. 2002. "Greenhouse Gas Reduction Policy in the United States: Identifying Winners and Losers in an Expanded Permit Trading System.” The Energy Journal 23: 1-18.

Shadbegian, Ronald J., Wayne Gray and Cynthia Morgan, 2004. "The 1990 Clean Air Act Amendments: Who Got Cleaner and Who Paid for It?” Working paper, University of Massachusetts, Dartmouth.

Shapiro, Matthew and Joel Slemrod, 1994. "Consumers Response to the Timing of Income: Evidence from a Change in Tax Withholding,” American Economic Review 85: 274-83.

Sieg, Holger, V. Kerry Smith, H. Spencer Banzhaf, and Randy Walsh, 2004. "Estimating the General Equilibrium Benefits of Large Changes in Spatially Delineated Public Goods.” International Economic Review 45: 1047-1077.

Slesnick, Daniel T., 1994. “Consumption, Needs, and Inequality.” International Economic Review 35: 677-703.

Smith, V. Kerry and Ju-Chin Huang, 1995. "Can Markets Value Air Quality? Meta-Analysis of Hedonic Property Value Models.” Journal of Political Economy 103: 209-27.

Souleles, Nicholas S., 1999. "The Response of Household Consumption to Income Tax Refunds.” American Economic Review 89: 947-958.

Souleles, Nicholas S., 2002. “Consumer Response to the Reagan Tax Cuts.” Journal of Public Economics 85: 99-120.

Stevens, Brandt and Adam Rose, 2002. "A Dynamic Analysis of the Marketable Permits Approach to Global Warming Policy: A Comparison of Spatial and Temporal Flexibility.” Journal of Environmental Economics and Management 44: 45-69. 
Stoft, Steven., 1993. “Appliance Standards and the Welfare of Poor Families.” The Energy Journal 14: 123-128.

Sutherland, Ronald J. 1991. “Market Barriers to Energy-Efficiency Investments,” The Energy Journal 12: 15-34.

Sutherland, Ronald J., 1994. “Income Distribution Effects of Electric Utility DSM Programs.” The Energy Journal 15: 103-118.

US Census Bureau, 2004. Statistical Abstract of the United States: 2004-2005. Washington, DC.

Viscusi, W. Kip and Joseph E. Aldy, 2003. "The Value of a Statistical Life: A Critical Review of Market Estimates throughout the World.” Journal of Risk and Uncertainty 27: 5-76.

Walls, Margaret and Jean Hanson, 1999. "Distributional Aspects of an Environmental Tax Shift: The Case of Motor Vehicles Emissions Taxes.” National Tax Journal 52: 53-65.

West, Sarah E., 2004a. “Distributional Effects of Alternative Vehicle Pollution Control Policies.” Journal of Public Economics 88: 735-757.

West, Sarah E., 2004b. “Equity Implications of Vehicle Emissions Taxes.” Journal of Transport Economics and Policy, forthcoming.

West, Sarah E., and Roberton C. Williams III, 2004. "Estimates from a Consumer Demand System: Implications for the Incidence of Environmental Taxes.” Journal of Environmental Economics and Management 47: 535-558.

Wier, Mette, Katja Birr-Pedersen, Henrik Klinge Jacobsen and Jacob Klok, 2005. “Are CO2 Taxes Regressive? Evidence from the Danish experience” Ecological Economics 52: 239-251.

Wiese, Arthur M, Rose, Adam, Schluter, Gerald. 1995. "Motor-Fuel Taxes and Household Welfare: An Applied General Equilibrium Analysis.” Land Economics 71: 229-43.

Williams, Roberton C., III, 2004. “An Estimate of the Second-Best Optimal Gasoline Tax, Considering Both Efficiency and Equity.” Working paper, University of Texas at Austin.

Williams, Roberton C., III, 2005. “Optimal Commodity Taxes, Public Good Provision, and Pollution Taxes: Reconciling Results from Representative-Agent and Multiple-Agent Models.” Working paper, University of Texas at Austin.

Willig, Robert D., 1976. “Consumer’s Surplus Without Apology.” American Economic Review 66: 589597.

Wolverton, Anne, 2002. “Does Race Matter? An Examination of a Polluting Plant's Location Decision.” Mimeo, US Environmental Protection Agency, Washington, DC.

Wolverton, Ann, 2003. “The Demographic Distribution of Pollution: Does Neighborhood Composition Affect Plant Behavior.” Mimeo, US Environmental Protection Agency, Washington, DC.

Yandle, T. and Burton, D., 1996. "Re-Examining Environmental Justice: a Statistical Analysis of Historical Hazardous Waste Landfill Siting Patterns in Metropolitan Texas.” Social Science Quarterly 77: 
477-492.

Zeldes, Stephen, 1989. “Consumption and Liquidity Constraints: An Empirical Investigation.” Journal of Political Economy 97: 305-346.

Zupan, J., 1973. The Distribution of Air Quality in the New York Region. Johns Hopkins University Press, Baltimore. 
Figure 1. Burden of a Product Tax

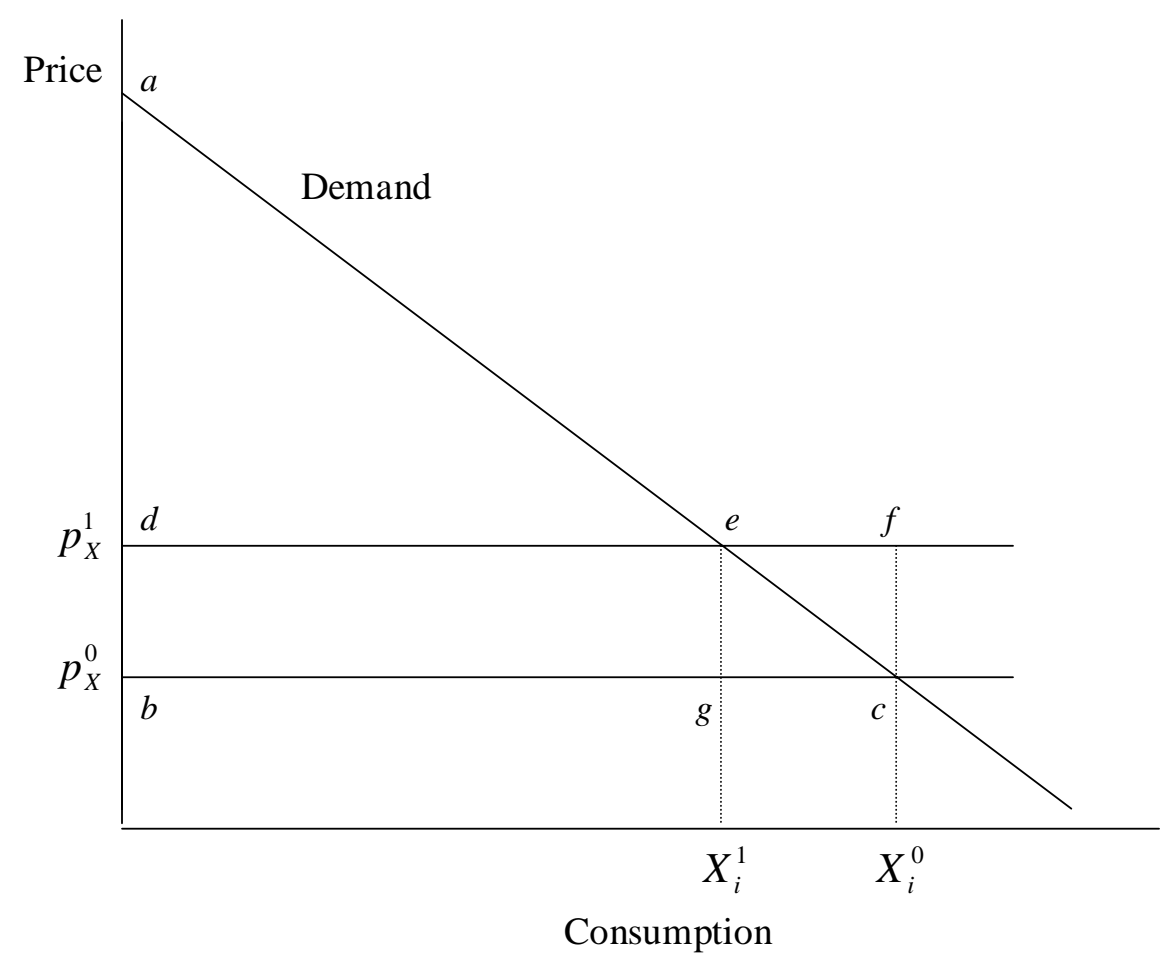

Figure 2. Abatement Under an Emissions Tax

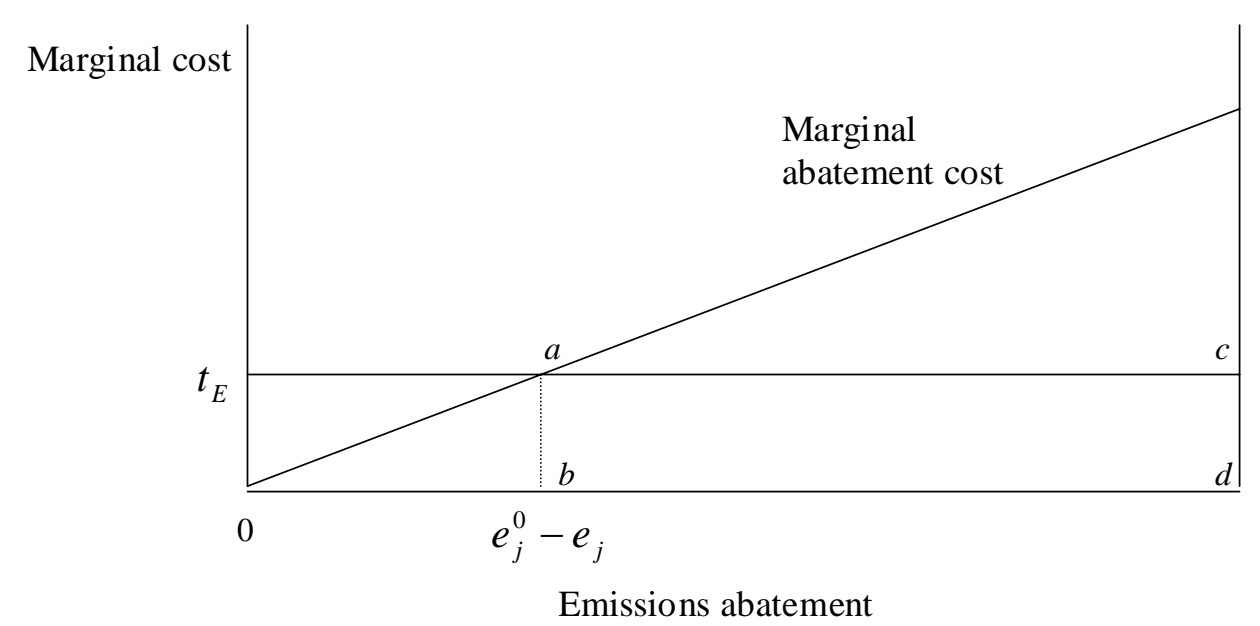

